\title{
Marriage and Divorce since World War II: Analyzing the Role of Technological Progress on the Formation of Households
}

Jeremy Greenwood, University of Pennsylvania and NBER

Nezih Guner, Universidad Carlos III de Madrid, CEPR, and IZA

\section{Introduction}

Consider the following two facts that have helped reshape U.S. households over the last 50 years:

1. A smaller proportion of the adult population is now married compared with 50 years ago (fig. 1). ${ }^{1}$ In $1950,82 \%$ of the female population was married (out of nonwidows between the ages of 18 and 64). By 2000 this had declined to $62 \%$. Adults now spend a smaller fraction of their lives married. In 1950 females spent about $88 \%$ of their life married as compared with $60 \%$ in 1995 . Underlying these facts are two factors:

a) Between 1950 and 1990, the divorce rate doubled from 11 to 23 divorces per 1,000 married women (between the ages of 18 and 64; see fig. 2).

b) At the same time, the marriage rate declined. Exactly how much is somewhat sensitive to the particular age group used in the denominator for the calculations. In 1950 there were 211 marriages per 1,000 unmarried women as compared with just 82 in 2000 (again, out of nonwidows between the ages of 18 and 64).

2. The amount of time allocated to market work by married households has increased markedly over the postwar period (see fig. 3). This is mainly due to a rise in labor force participation by married females. In particular:

a) In 1950 a married household in the 24-54-year-old age group spent working in the market 25.5 hours per week per person, compared with 31.3 hours per week in a single household. Thus, singles worked more in the market on average than married couples. At the time, only $23.7 \%$ of married women worked, compared with $78 \%$ of single ones. 

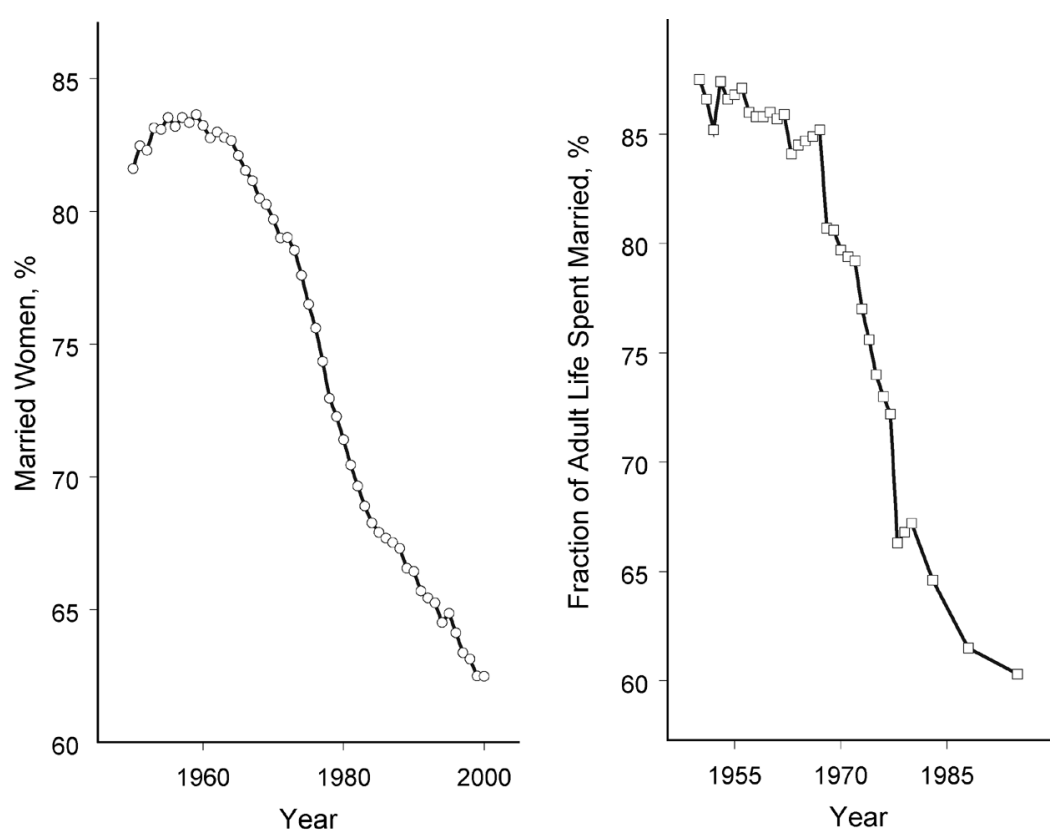

Fig. 1. Marriage, 1950-2000

b) By the year 1990 labor effort expended per person by married households had risen to 33.5 hours per week. This exceeded the 30.6 hours spent by a single household. Almost as many married females were participating in the labor market $(71 \%)$ as single ones (80\%).

What economic factors can explain these facts? The idea here is that technological progress played a major role in inducing these changes. ${ }^{2}$ Two hundred years ago the United States was largely a rural economy. The household was the basic production unit, with the family producing a large fraction of what it consumed. At the time, most marriages were arranged by the parents of young adults. Key considerations were whether or not the potential groom would be a good provider and the bride a good housekeeper. ${ }^{3}$ Over time more and more household goods and services could be purchased outside the home, such as packaged foods and ready-made clothes. Additionally capital goods, ranging from washing machines to microwave ovens, were brought into the home, greatly reducing the time needed to maintain a household. This had two effects. First, it allowed all adults, both married and single, to devote more time to market activities and less to household production. Second, it lowered the economic incentives to get married by reducing the benefits 


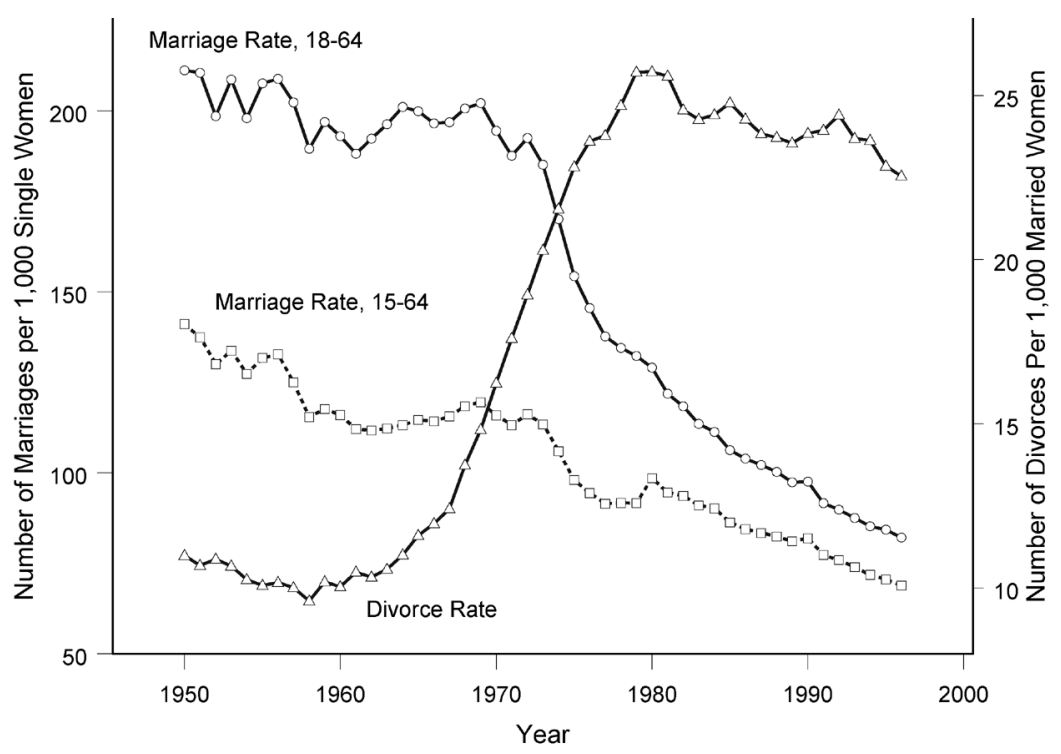

Fig. 2. Rates of marriage and divorce, 1950-2000

of the traditional specialization of women at housework and of men at market work. The reduction of the economic benefits of marriage allowed the modern criteria of mutual attraction between mates to come to the fore, a trend "from economics to romance" in the words of Ogburn and Nimkoff (1955).

To model this idea formally, a Becker (1965)-cum-Reid (1934) model of household production is embedded into a Mortensen (1988) style spousal-search model. Three key ingredients are injected into this framework. First, there are economies of scale in household consumption and production. Second, it is assumed that purchased household inputs and labor are substitutes in household production. Third, it is presumed that nonmarket goods exhibit stronger diminishing marginal utility than market goods. Some theoretical results are established for this framework. The economies of scale in household consumption and production provide an economic motive for marriage. It pays for a couple to pool their resources together. Now, suppose that the price of purchased household inputs declines over time. Labor will be displaced from the home, given that household inputs and labor are substitutes in household production. Furthermore, if there is stronger diminishing marginal utility in nonmarket goods vis-à-vis market goods, then married households will allocate a smaller fraction of their spending on the inputs for household 

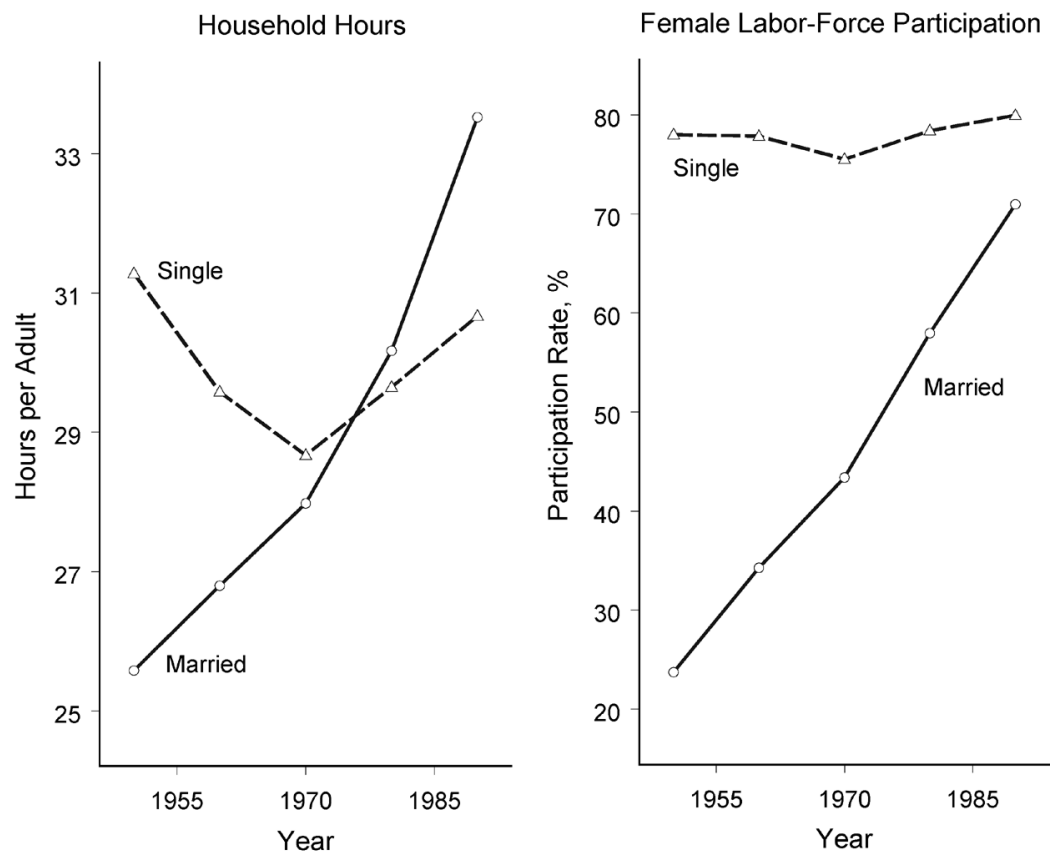

Fig. 3. Household hours worked and female labor force participation, 1950-90

production than less well off single households. As a consequence, single households gain the most from a decline in the price of purchased household inputs. Thus, a fall in the price of purchased household inputs causes the relative benefits of single life to increase. Singles searching for a spouse will become pickier. For those currently married, the value of a divorce will rise, because the value of becoming single is higher. Thus, the theoretical analysis suggests that the framework developed has promise for explaining the observed rise in the number of single households, together with the increase in hours worked by married ones.

To gauge the quantitative potential of the framework, the model is solved numerically. The model's predictions for the time paths of labor force participation and vital statistics are compared with the U.S. data. It is found that the developed framework can potentially explain a substantial portion of the rise in divorce, the fall in marriage, and the increase in married female labor force participation that occurred during the later half of the twentieth century.

Interestingly, the fraction of the population that is married did not show a monotonic decline over the course of the entire twentieth century. 
It actually increased during the baby boom years. This resulted in a hump-shaped time path for marriage during the last century. Is this observation congruent with theory presented here? The answer is yes. It is demonstrated that a simple extension of the basic framework has the potential to address this fact. It does so by linking a young adult's decision to leave home and search for a mate with technological progress in the household sector. The extension can explain the drop in the number of young adults living with their parents over the last 100 years.

A prediction of the framework is that household size should decline when the price of purchased household inputs falls. The relationship between household size and the price of household appliances is examined econometrically for a small cross section of Western countries. A positive association is found, in accordance with the theory's prediction. This finding complements recent work by Cavalcanti and Tavares (2008), who report that female labor supply is negatively associated with the price of household appliances in a panel of countries. Algan and Cahuc (2007) also find that it is related to the labor supply of younger and older (non-prime-age) workers, but in a way that interacts with cultural differences across countries. Likewise, Coen-Pirani, Leon, and Lugauer (2008) conclude, using U.S. Census micro data, that a significant portion of the rise in married female labor force participation during the 1960s can be attributed to the diffusion of household appliances.

It needs to be stated up-front that the goal of the analysis is not to simulate an all-inclusive model of household formation and labor force participation. Rather, the idea here is to see whether or not the simple mechanisms put forth have the potential quantitative power to explain the postwar observations on household formation and labor force participation. This is done without regard to the many other possible explanations for the same set of facts-some of which could be embedded into a more general version of the developed framework. Theory, by its essence, is a process of abstraction. Therefore, some factors that may be important for understanding the phenomena under study have been deliberately left out of the analysis, for purposes of both clarity and tractability; see Stevenson and Wolfers (2007) for a recent survey on marriage and divorce.

For example, the tremendous amount of technological progress in contraception that occurred over the last century greatly reduced the risk of out-of-wedlock sexual relationships. It seems very likely that this provided impetus for the fall in marriage and the rise in divorce that occurred since World War II. It might be hard for a theory based on improvements in contraception alone, however, to explain the hump-shaped time path 
for marriage that occurred over the entire century. The liberalization of divorce laws in the 1970s is often thought of as being a prime candidate for causing the rise in divorce. The adoption of no-fault unilateral divorce laws by many states in the 1970s coincides well with the rise of the divorce rate during the same period. The empirical evidence on the effect of divorce laws is controversial, however. A recent study by Wolfers (2006) finds that, once transitional dynamics are appropriately controlled for, unilateral divorce laws explain very little of the long-run rise in divorce rates. Furthermore, except for a spike associated with World War II, the rate of divorce rose more or less continuously over the last century from about four per 1,000 women in 1900, to about 10 in 1941 (a doubling), to about 23 today (another doubling). (In fact, Ogburn and Nimkoff [1955] write about the early trend.) So, there seems to be room in the literature for the explanation proposed here that technological advance in the household sector contributed to the rise in divorce and the decline in marriage.

\section{The Economic Environment}

The economy is populated by a continuum of males and females, each sex with unit mass. Individuals have finite lives. Specifically, at the beginning of each period an individual faces the constant probability of dying, $\delta$. Thus, $\delta$ people of each sex die each period. The individuals who have passed on are replaced by a newly born generation of exactly the same size. There are two types of individuals: those who are single and those who are married. Each individual is endowed with one unit of time, which can be divided between market and nonmarket work. A unit of market work pays the wage rate, $w$. At the beginning of each period, singles participate in a marriage market, assuming that they have survived. Each single is randomly paired up with someone else. The prospective couple then draws a certain level of suitability or quality, $b$, from a fixed distribution. The question facing a single is, should she or he marry or wait until a better match comes along? For a married couple, match quality evolves over time, according to some fixed distribution. For simplicity, assume that married couples die together at the start of a period with probability $\delta$. If they survive, then they must decide whether or not to remain married. After the marriage and divorce decisions, individuals enter the labor market. A single agent must decide how much of his or her one unit of time to devote to market work. A married couple must determine how much of their two units of time to spend 
in the labor force. For simplicity, it is assumed that there are no asset markets. Hence, there is no borrowing or lending, and so forth, in the economy. Finally, as will become clear, there are no matching externalities present in the model. The aggregate state of the marriage market will not influence a household's decision making.

\section{A. Production}

Start with production. Two types of goods are produced, market and nonmarket ones.

\section{Household Production}

Suppose that nonmarket goods, $n$, are produced in line with the following household production function:

$$
n=\left[\theta d^{\kappa}+(1-\theta) h^{\kappa}\right]^{1 / \kappa} \text { for } 0<\kappa<1,
$$

where $d$ denotes purchases of household inputs, and $h$ is the amount of time spent on housework. Let purchased household inputs sell at price $p$, measured in terms of time. The idea here is that over time $p$ will drop. Specifically, let $p$ fall monotonically to some lower bound $p>0$. In response households will substitute out of using labor toward using more purchased inputs. Note that it has been assumed that purchased inputs and time are more substitutable in production than Cobb-Douglas, that is, $\kappa>0$. Hence, as $p$ declines, household production will become more goods intensive and less labor intensive. Examples of laborsaving household inputs abound: disposable diapers, frozen foods, microwave ovens, washing machines, and Tupperware.

\section{Market Production}

Market goods are produced in line with the constant-returns-to-scale production technology

$$
\mathbf{y}=w \mathbf{1},
$$

where $\mathbf{y}$ is aggregate output and $\mathbf{l}$ is aggregate employment. Given the linear form for the aggregate production function, $w$ will represent the real wage rate in equilibrium. Real wages will grow over time. In particular, suppose that $w$ increases monotonically to some finite upper bound $\bar{w}$. There is no physical or, as mentioned, financial capital in the 
economy. Market output $y$ is used for two purposes, namely, direct consumption and as an input into household production. Specifically, one unit of output can be used to produce one unit of final consumption or $1 /(w p)$ units of household inputs. Thus, the economy's resource constraint reads

$$
\mathbf{c}+w p \mathbf{d}=\mathbf{y},
$$

where $\mathbf{c}$ and $\mathbf{d}$ represent aggregate consumption and purchases of household inputs, respectively.

\section{B. Tastes}

Singles. Let the momentary utility function for a single read

$$
U^{s}(c, n)=\alpha \ln (c-\mathbf{c})+(1-\alpha) n^{\zeta} / \zeta, \quad \text { with } 0<\alpha<1, \zeta<0 \leq \mathbf{c} .
$$

Here $c$ and $n$ denote the person's consumption of market and nonmarket goods, respectively. The constant $\mathbf{c}$ is a fixed cost associated with maintaining a household. This represents the first of two sources of scale economies in household consumption. Note that the utility function for nonmarket goods is more concave than the ln function (i.e., $\zeta<0$ ). The importance of this restriction will become clear as the theory is developed. This constraint is not imposed in the quantitative analysis. Therefore, the data will speak to the sign and magnitude of $\zeta$. If a single dies, he realizes a utility level of zero in the afterlife, an innocuous normalization. Leisure has been excluded from the tastes. This is in line with the Beckerian $(1965,504)$ theory of household production since "although the social philosopher might have to define precisely the concept of leisure, the economist can reach all his traditional results as well as many more without introducing it at all." The idea here is that often all one cares about is time spent in the market versus at home, and the above framework will capture this through the production side of things. Additionally, observe that a separable form for the utility function is chosen, as is conventional in macroeconomics. This minimizes the role placed on home production.

Married individuals. Tastes for a married individual are given by

$$
U^{m}(c, n)+b=\alpha \ln \left[(c-\mathbf{c}) / 2^{\phi}\right]+(1-\alpha)\left(n / 2^{\phi}\right)^{\zeta} / \zeta+b, \quad \text { with } 0<\phi<1,
$$

where $c$ and $n$ represent the household's consumption of market and nonmarket goods. To determine an individual's consumption, $c-\mathbf{c}$ and $n$ are divided by the household equivalence scale, $2^{\phi}$, to get consumption per member, $(c-\mathbf{c}) / 2^{\phi}$ and $n / 2^{\phi}$. Since $0<\phi<1$, this implies that it is 
less expensive to provide the second member of the household with consumption than it is the first. This is the second source of economies of scale in consumption. Observe that the bliss from a match, $b$, can be negative. Finally, if a married couple die, they realize a zero-utility level thereafter.

\section{Match Quality}

Recall that when singles meet they draw a match quality $b$. Suppose that $b$ is normally distributed so that

$$
b \sim N\left(\mu_{s}, \sigma_{s}^{2}\right),
$$

where $\mu_{s}$ and $\sigma_{s}^{2}$ are the mean and variance of the singles distribution. Let the cumulative distribution function that singles draw from be represented by $S(b)$. Likewise, each period a married couple draws a new value for the match quality variable, $b$. Suppose that last period the couple had a match quality of $b_{-1}$. Now, assume that $b$ evolves according to the following autoregressive process:

$$
b=(1-\rho) \mu_{m}+\rho b_{-1}+\sigma_{m} \sqrt{1-\rho^{2}} \xi, \quad \text { with } \xi \sim N(0,1) .
$$

Here $\mu_{m}$ and $\sigma_{m}^{2}$ denote the long-run mean and variance for the process $b$. The parameter $\rho$ is the coefficient of autocorrelation. Write the (conditional) cumulative distribution function that married couples draw from as $M\left(b \mid b_{-1}\right)$.

\section{Household Decision Making}

How will a single agent divide his or her time between market and nonmarket work? When will he or she choose to get married? Likewise, how will a married couple split their time between market work and housework? When will they choose to divorce? To answer these questions, let $V(b)$ denote the expected lifetime utility for an individual who is currently in a marriage with match quality $b$. Similarly, $W$ will represent the expected lifetime utility for an agent who is single today. Imagine that two singles meet and draw a match quality of $b$. They will choose to marry if $V(b) \geq W$ and to remain single if $V(b)<W$. Likewise, consider a married couple with match quality $b$. They will choose to remain married when $V(b) \geq W$ and choose to divorce if $V(b)<W$. Thus, the marriage and divorce decisions are summarized by table 1 . Note that given the absence of asset markets, $b$ will be the only state variable at the individual level that is relevant for determining expected lifetime utility. 
Table 1

Marriage and Divorce Decisions

\begin{tabular}{llll}
\hline \multicolumn{2}{c}{ Single } & \multicolumn{2}{c}{ Married } \\
\hline Marry if & $V(b) \geq W$ & Remain married if & $V(b) \geq W$ \\
Remain single if & $V(b)<W$ & Divorce if & $V(b)<W$ \\
\hline
\end{tabular}

At the aggregate level, prices and wages will also matter. Recall that wages are rising over time and that prices are falling. Thus, $W$ and $V$ are functions of time. Given this, $W^{\prime}$ and $V^{\prime}$ will denote the value functions for single and married lives that obtain next period; that is, the prime symbol connotes these functions' dependence on time. So, how are the functions $V(b)$ and $W$ determined? This question will be addressed next.

\section{A. Singles}

The dynamic programming problem for a single agent appears as

$$
W=\max _{c, n, d, h}\left\{U^{s}(c, n)+\beta \int \max \left[V^{\prime}\left(b^{\prime}\right), W^{\prime}\right] d S\left(b^{\prime}\right)\right\}
$$

subject to

$$
c=w(1-h)-w p d
$$

and (1). The discount factor $\beta$ reflects the probability of dying. That is, if $\tilde{\beta}$ is the person's subjective discount factor, then $\beta=(1-\delta) \tilde{\beta}$. Observe that while the individual is single today, the agent picks married or single life next period to maximize welfare, as the term $\max \left[V^{\prime}\left(b^{\prime}\right), W^{\prime}\right]$ in (P1) makes clear. Again, recall that the value functions are dependent on technology and hence time. Therefore, for a given level of match quality, $b$, the value function will return a different level of expected utility tomorrow versus today. This dependence of the value functions on time is implicitly indicated through the use of the prime symbols attached to $V$ and $W$, which differentiates their functional forms tomorrow from their forms today. Since $S(b)$ is some fixed distribution, the aggregate state of the marriage market does not affect the individual's decision making.

\section{B. Couples}

The dynamic programming problem for a married couple reads

$$
V(b)=\max _{c, n, d, h}\left\{U^{m}(c, n)+b+\beta \int \max \left[V^{\prime}\left(b^{\prime}\right), W^{\prime}\right] d M\left(b^{\prime} \mid b\right)\right\}
$$


subject to

$$
c=w(2-h)-w p d
$$

and (1). Problem (P2) is similar in structure to problem (P1) with three differences: (i) the utility function for married agents differs from that for single agents because of scale effects in household consumption; (ii) a married couple realizes bliss from marriage, and this is autocorrelated over time; and (iii) the couple has two units of time to allocate between market and nonmarket work. Again, note that while an individual is married today, the agent chooses married or single life next period to maximize welfare. Finally, the aggregate state of the marriage market does not impinge on the couple's decision making because $M\left(b^{\prime} \mid b\right)$ is a fixed distribution.

\section{Equilibrium}

Formulating an equilibrium to the above economy is surprisingly simple. First, given the linear market production function (2), there is no need to determine the equilibrium wage, $w$. Second, since there are no financial markets, there is no interaction between households other than through the marriage market. As far as consumption and production are concerned, each household is an island unto itself. Also, there are no matching externalities in the model. Each single is matched with a potential mate each period. This pair then draws a quality for the match, $b$, from the fixed distribution $S(b)$. Likewise, the $b$ for a couple evolves according to the fixed distribution $M\left(b^{\prime} \mid b\right)$. Hence, household decision making is not influenced by the aggregate state of the marriage market. Therefore, characterizing an equilibrium for the economy amounts to solving the programming problems (P1) and (P2). Thus, it is easy to establish that an equilibrium for the above economy both exists and is unique.

Vital statistics. Computing vital statistics for the economy is a relatively straightforward task. Suppose that the economy exits the previous period with the (nonnormalized) distribution $\mathbf{M}_{-1}\left(b_{-1}\right)$ over match quality for married agents of a particular sex. The fractions of agents (of a particular sex) who were married and single last period, $m_{-1}$ and $s_{-1}$, are therefore given by $m_{-1}=\int d \mathbf{M}_{-1}\left(b_{-1}\right)$ and $s_{-1}=1-\int d \mathbf{M}_{-1}\left(b_{-1}\right)$. Now, at the beginning of the current period the fraction $\delta$ of the populace dies. These people are replaced by newly born single agents. All agents will then take a draw, $b$, for their match quality. After this, they will make their marriage and divorce decisions in line with table 1. Define the set of 
match quality shocks for which it is in an individual's best interest to live in a married household, or $\mathcal{M}$, by

$$
\mathcal{M}=\{b: V(b) \geq W\} .
$$

The current-period distribution over match quality for married agents, or $\mathbf{M}(b)$, will then read ${ }^{4}$

$$
\begin{aligned}
\mathbf{M}(b)= & (1-\delta) \iint_{\mathcal{M} \cap[-\infty, b]} d M\left(\tilde{b} \mid b_{-1}\right) d \mathbf{M}_{-1}\left(b_{-1}\right) \\
& +\left(s_{-1}+\delta m_{-1}\right) \int_{\mathcal{M} \cap[-\infty, b]} d S(\tilde{b}) .
\end{aligned}
$$

Therefore, the fractions of agents who are married and single in the current period, $m$ and $s$, are given by $m=\int d \mathbf{M}(b)$ and $s=1-\int d \mathbf{M}(b)$. The fraction of people getting married in the current period is $\left(s_{-1}+\delta m_{-1}\right) \int_{\mathcal{M}} d S(\tilde{b})$, and the proportion going through a divorce is given by

$$
(1-\delta) \int_{\mathcal{M}^{c}} \int d M\left(\tilde{b} \mid b_{-1}\right) d \mathbf{M}_{-1}\left(b_{-1}\right),
$$

where $\mathcal{M}^{c}$ is the complement of $\mathcal{M}$.

\section{Qualitative Analysis}

It is now time to entertain the following two questions, at least at a theoretical level:

1. How does technological progress affect the amount of time spent on housework?

2. How does technological progress affect the economic return from married versus single life?

\section{A. The Time Allocation Problem}

The problem. To this end, consider the time allocation problem that faces a household of size $z$. It is static in nature and appears as

$$
I(z, p, w)=\max _{c, n, h, d}\left\{\alpha \ln \left(\frac{c-\mathbf{c}}{z^{\phi}}\right)+(1-\alpha)\left(\frac{n}{z^{\phi}}\right)^{\zeta} / \zeta\right\}
$$

subject to

$$
c-\mathbf{c}=w(z-h)-w p d-\mathbf{c}
$$


and

$$
n=\left[\theta d^{\kappa}+(1-\theta) h^{\kappa}\right]^{1 / \kappa} .
$$

Observe that versions of problem (P3) are embedded into (P1) and (P2), a fact that can be seen by setting $z=1$ and $z=2$.

The solution. By using the constraints for $c-\mathbf{c}$ and $n$ in the objective function (P3) and then maximizing with respect to $d$ and $h$, the following two first-order conditions obtain:

$$
\frac{\alpha}{c-\mathbf{c}} w p=(1-\alpha) z^{-\phi \zeta}\left[\theta d^{\kappa}+(1-\theta) h^{\kappa}\right]^{\zeta / \kappa-1} \theta d^{\kappa-1}
$$

and

$$
\frac{\alpha}{c-\mathbf{c}} w=(1-\alpha) z^{-\phi \zeta}\left[\theta d^{\kappa}+(1-\theta) h^{\kappa}\right]^{\zeta / \kappa-1}(1-\theta) h^{\kappa-1} .
$$

These two first-order conditions have standard interpretations. For instance, the left-hand side of (7) represents the marginal cost of an extra unit of purchased household inputs, $d$. The marginal unit of purchased household inputs costs $w p$ in terms of forgone market consumption. Since an extra unit of market consumption has a utility value of $\alpha /(c-\mathbf{c})$, this leads to a sacrifice of $[\alpha /(c-\mathbf{c})] w p$ in terms of forgone utility. Likewise, the right-hand side of this equation gives the marginal benefit of an extra unit of purchased household inputs. These extra goods will increase household production by $\left[\theta d^{\kappa}+(1-\theta) h^{\kappa}\right]^{1 / \kappa-1} \theta d^{\kappa-1}$. The marginal utility of nonmarket goods is $(1-\alpha) z^{-\phi \zeta} n^{\zeta-1}$. Thus, the marginal benefit of an extra unit of purchased household inputs is

$$
(1-\alpha) z^{-\phi \zeta} n^{\zeta-1} \times\left[\theta d^{\kappa}+(1-\theta) h^{\kappa}\right]^{1 / \kappa-1} \theta d^{\kappa-1},
$$

which is the right-hand side of (7). The two first-order conditions (7) and (8), in conjunction with the budget constraint (6), determine a solution for $c, d$, and $h$.

\section{B. Results}

Everything is now set up to address the two questions posed at the start of this section.

1. Technological Progress and Time Allocations

So, how does technological progress affect the amount of time allocated to homework? First, a fall in the price of purchased household inputs, $p$, 
leads to a reduction in the amount of housework, $h$, and a rise in the amount of market work, $z-h$. When the price of purchased household inputs drops, households move away from using labor in household production toward using goods (given the assumption that production exhibits more substitutability than Cobb-Douglas or that $\kappa>0$ ). Second, a rise in wages, $w$, leads to an increase in the amount of housework, $h$, done. At low levels of income, the marginal utility of market goods is high because of the fixed cost of household maintenance, $\mathbf{c}$. Thus, people devote a lot of time to laboring in the market. As wages increase, the fixed cost for household maintenance bites less and people relax their work effort in the market. Proposition 1 formalizes all of this.

Proposition 1. Housework, $h$, is

i) increasing in the price of household commodities, $p$;

ii) decreasing in the fixed cost of household maintenance, $\mathbf{c}$; and

iii) increasing in real wages, $w$ (when $\mathrm{c}>0$ ).

Proof. See the appendix.

Remark. Real wages, $w$, will have no effect on time allocations in the absence of a fixed cost for household maintenance, $\mathbf{c}$, that is, when $\mathbf{c}=0$. To see this, substitute (6) into (7) and (8) and note that the first-order conditions depend on $\mathbf{c} / w$. Thus, as the economy develops, the impact of wages on housework will vanish, since $\mathbf{c} / w \rightarrow 0$ as $w \rightarrow \infty$.

\section{Household Size and Allocations}

Can anything be said about the allocations $(c, d, h)$ within a two-person household vis-à-vis a one-person household? The lemma below provides the answer, where the superscripts $m$ and $s$ are attached to the allocations for married and single households. Before proceeding, note that the lemma is a key step along the road to proving that a fall in the price for purchased household inputs reduces the utility differential between married and single life, when the amount of marital bliss is held fixed. It shows that a married household spends less on purchased household inputs, relative to market consumption (over and above the fixed cost of household maintenance), than a single one. Likewise, the corollary to the lemma is instrumental for establishing that a rise in wages reduces the economic benefit from marriage. It proves that a married household consumes more market goods than a single household does. 
Lemma 1. The allocations in married and single households have the following relationships:

i) $c^{m}-\mathbf{c}>[(2-\mathbf{c} / w) /(1-\mathbf{c} / w)]\left(c^{s}-\mathbf{c}\right)$;

ii) $d^{m}<[(2-c / w) /(1-\mathbf{c} / w)] d^{s}$;

iii) $h^{m}<[(2-\mathbf{c} / w) /(1-\mathbf{c} / w)] h^{s}$.

The above relationships hold even when $\mathrm{c}=0$. They adhere with equality when $\zeta=0$.

Proof. Again, see the appendix.

Corollary. Married households consume more market goods than single households:

i) $\left(c^{m}-\mathbf{c}\right) / 2^{\phi}>c^{s}-\mathbf{c}$;

ii) $c^{m}>c^{s}$.

The above relationships hold even when $\mathrm{c}=\zeta=0$.

Proof. See the appendix.

Now, note that a married household has $2-\mathbf{c} / w$ units of disposable time, after netting out the fixed cost of household maintenance, to spend on various things. A single household has $1-\mathbf{c} / w$ units of disposable time. Lemma 1 states that a married household will spend a larger fraction of its adjusted time endowment on the consumption of market goods than a single household will. The lemma also implies that married households spend less than single households do on household inputs, relative to market goods. That is, $w p d^{m} /\left(c^{m}-\mathbf{c}\right)<w p d^{s} /\left(c^{s}-\mathbf{c}\right)$ and $w h^{m} /$ $\left(c^{m}-\mathbf{c}\right)<w h^{s} /\left(c^{s}-\mathbf{c}\right)$ so that $\left(w p d^{m}+w h^{m}\right) /\left(c^{m}-\mathbf{c}\right)<\left(w p d^{s}+w h^{s}\right) /$ $\left(c^{\mathcal{S}}-\mathbf{c}\right)$, at least when $\zeta<0$. When nonmarket goods exhibit strong diminishing marginal utility, bigger households will favor (relative to the consumption patterns of smaller ones) the use of market consumption for their larger adjusted endowments of time. Part $i$ of the corollary states that after the fixed cost of household maintenance is paid, market consumption per person is effectively higher in a married household than in a single one. Also, married households spend more in total on market goods than single households.

3. Technological Progress and the Economic Benefits of Married versus Single Life

Finally, how does technological progress affect the utility differential between married and single life (with the amount of marital bliss held fixed)? To address this, let $u^{m}$ denote the level of momentary utility realized 
from married life, without marital bliss, and $u^{s}$ represent the level of utility realized from single life. From problem (P3) it is apparent that $u^{m}=$ $I(2, p, w)$ and $u^{s}=I(1, p, w)$.

Proposition 2. The utility differential between married and single life (without marital bliss), $u^{m}-u^{s}$, is

i) increasing in the price of purchased household inputs, $p$, and

ii) decreasing in real wages, $w$ (when $\mathrm{c}>0$ ).

Proof. The first part of the proposition can be established by applying the envelope theorem to problem (P3). It can be calculated that

$$
\frac{d\left(u^{m}-u^{s}\right)}{d w}=-\alpha w\left(\frac{d^{m}}{c^{m}-\mathbf{c}}-\frac{d^{s}}{c^{s}-\mathbf{c}}\right)>0,
$$

where the sign of the above expression follows from parts $i$ and ii of lemma 1 . To prove the second part of the lemma, note that

$$
\begin{aligned}
\frac{d\left(u^{m}-u^{s}\right)}{d w} & =\alpha\left(\frac{2-h^{m}-p d^{m}}{c^{m}-\mathbf{c}}-\frac{1-h^{s}-p d^{s}}{c^{s}-\mathbf{c}}\right) \\
& =\frac{\alpha}{w}\left(\frac{c^{m}}{c^{m}-\mathbf{c}}-\frac{c^{s}}{c^{s}-\mathbf{c}}\right)=\frac{\alpha}{w}\left(\frac{1}{1-\mathbf{c} / c^{m}}-\frac{1}{1-\mathbf{c} / c^{s}}\right)<0,
\end{aligned}
$$

where the sign of the above expression derives from the fact that $c^{m}>c^{s}$, or part ii of the corollary to lemma 1. QED

Thus, technological advance in the form of either a falling price for purchased household inputs or rising real wages reduces the economic gain from marriage. A fall in the price of purchased household inputs leads to a substitution away from the use of labor in household production toward the use of purchased household inputs. Single households use laborsaving products the most intensively, so they realize the greatest gain, that is, $d^{m} /\left(c^{m}-\mathbf{c}\right)<d^{s} /\left(c^{s}-\mathbf{c}\right)$ in (9). The assumption of strong diminishing marginal utility for nonmarket goods $(\zeta<0)$ is important for the result that a drop in the price of purchased household inputs will reduce the economic return to marriage. Suppose that $\zeta=0$. Then prices will have no impact on the utility differential between married and single life, because $d^{m} /\left(c^{m}-\mathbf{c}\right)=d^{s} /\left(c^{\mathcal{s}}-\mathbf{c}\right)$ by lemma 1 . The presence of a fixed cost is not important for obtaining the desired result, since the lemma still holds when $\mathbf{c}=0$. To take stock of the situation so far, a decline in the price of household products will lead to a decrease in housework by proposition 1 . It also causes a reduction in the economic return to marriage by 
proposition 2. Therefore, a decline in the price of purchased household inputs has the potential for explaining observations 1 and 2 made in the introduction.

As wages increase, the fixed cost for household maintenance matters less. The fixed cost for household maintenance bites the most for single households (i.e., $\mathbf{c} / c^{m}<\mathbf{c} / c^{s}$ in [10]). Therefore, single households benefit the most from a rise in wages. From (10) it is immediate that a change in wages will have no impact in the absence of a fixed cost $(\mathbf{c}=0)$ on the utility differential between married and single life. Also, note that this result does not depend on the assumption of strong diminishing marginal utility of nonmarket goods since the corollary to lemma 1 holds even when $\zeta=0$. Now, recall from proposition 1 that an increase in wages will cause housework to rise. Therefore, a rise in real wages alone cannot account for both observations 1 and 2 .

\section{The Economic Value of Marriage}

What is the economic value of married life? One way to measure this is to compute the required income, or compensation, that is necessary to make a single person as well off as a married one when there is no marital bliss $(b=0)$. The formula for the required compensation, expressed as a fraction of the value of a single individual's time endowment, is surprisingly simple and natural.

Lemma 2. The compensating differential between married and single life is given by

$$
\ln \left[E\left(p, w, u^{m}\right) / w\right]=\ln \left[2^{1-\phi}+\left(1-1 / 2^{\phi}\right) \mathbf{c} / w\right] .
$$

The result is very appealing and the underlying intuition straightforward. For expositional purposes, temporarily set $\mathbf{c}=0$. On the one hand, a married household has twice the time endowment of a single one. On the other hand, a married household must provide consumption to twice as many members. On net, owing to economies of scale in household consumption, a married household realizes $2^{1-\phi}\left(=2 / 2^{\phi}\right)$ as much consumption as a single one. Now, when $c>0$, an adjustment must be made for the presence of the fixed cost of household maintenance. This reduces a single's consumption by $\mathrm{c}$ but a married one's by only $\mathbf{c} / 2^{\phi}$, so that the difference is $\left(1-1 / 2^{\phi}\right)$ c. Note that the income needed to make a single person as well off as a married one is not a function of the price of purchased household inputs; one just needs to scale up a single's income by the constant fraction $2^{1-\phi}+\left(1-1 / 2^{\phi}\right) \mathbf{c} / w$. It is a 
function of the wage rate, though. At higher wage rates the fixed cost bites less. Finally, lemma 2 establishes that there is an economic incentive for marriage provided that there is some form of economies of scale in consumption or production, that is, whenever either $\mathbf{c}>0$ or $\phi<1$.

It may seem a bit puzzling that a fall in price reduces the utility differential between married and single life, $u^{m}-u^{s}$, but has no impact on the compensating differential between these two situations, $\ln \left[2^{1-\phi}+\right.$ $\left.\left(1-1 / 2^{\phi}\right) \mathbf{c} / w\right]$. This is true even when $\mathbf{c}=0$; that is, the impact of price on the difference in utility between married and single life is not due to the presence of the fixed cost. Suppose that one makes the compensation outlined by lemma 2 . Then, married and single households will use laborsaving products in the same intensity, in the sense that $d^{m} /\left(c^{m}-\right.$ c) $=d^{s} /\left(c^{s}-\mathbf{c}\right) \cdot{ }^{5}$ After the required compensation is made, a change in price will have no impact on the utility differential, $u^{m}-u^{s}$, as can readily be seen from (9). This suggests that the compensating differential is not a perfect measure to use for tracking over time the impact of technological progress on the utility differential from marriage.

\section{Quantitative Analysis}

The household's dynamic programming problems - a restatement. Given the static nature of the household's time allocation problem (P3), note that the dynamic programming problems for single and married households, (P1) and (P2), can be rewritten as

$$
W=I(1, p, w)+\beta \int \max \left[V^{\prime}\left(b^{\prime}\right), W^{\prime}\right] d S\left(b^{\prime}\right)
$$

and

$$
V(b)=I(2, p, w)+b+\beta \int \max \left[V^{\prime}\left(b^{\prime}\right), W^{\prime}\right] d M\left(b^{\prime} \mid b\right) .
$$

Here $I(z, p, w)$ gives the maximal level of momentary utility that a $z$-person household can obtain, given that the price of purchased household inputs is $p$ and that the wage rate is $w$. The fact that for a household of a particular size, $z$, it is possible to calculate its current level of utility, $I(z, p, w)$, without regard to its marriage/divorce decision is very useful. Given a sequence of prices and wages, $\left\{p_{t}, w_{t}\right\}_{t}^{\infty}$, it possible to compute from (P3) the associated sequence of momentary utilities for single and married households, $\left\{I\left(1, p_{t}, w_{t}\right), I\left(2, p_{t}, w_{t}\right)\right\}_{t}^{\infty}$. 


\section{A. Matching the Model with the Data}

In order to simulate the model, numbers must be selected for the various parameters. Except for five of the parameters, almost nothing is known about appropriate values. Additionally, time series for prices and wages need to be inputted into the simulation. Values for the model's parameters either will be assigned on the basis of a priori information or will be estimated.

\section{A Priori Information}

Take the model period to be 1 year. In line with convention, set the subjective discount factor at 0.96 . The discount factor used in decision making must reflect the individual's probability of survival, $1-\delta$. A person's life expectancy is $1 / \delta$. Thus, if (marriageable) life expectancy for an adult is taken to be 47 years, then $1 / \delta=47$. Therefore, set $\beta=0.96 \times$ $(1-1 / 47)$. Next, let $\phi=0.77$. This is in line with the Organization for Economic Cooperation and Development's household equivalence scale that treats the second adult in a family as consuming an additional 0.7 times the amount of the first adult. Hence, the parameter $\phi$ solves $1 / 2^{\phi}=1 /(1.0+0.7)$. A series for wages can be constructed from the U.S. data. To do this, divide disposable income by hours worked to obtain a measure of compensation per hour. The use of disposable income should (partially) take into account the changes in taxes (and transfer payments) that occurred over this time period. Between 1950 and 2000 compensation per hour worked rose 3.0 times. Thus, the analysis simply presumes that wages rise at $100 \times \ln (3.0) / 50=2.2 \%$ per year. Finally, the household production function is characterized by two parameters, namely, $\kappa$ and $\theta$. These have been estimated by McGrattan, Rogerson, and Wright (1997). Their numbers are used here. ${ }^{6}$

\section{Estimation}

The rest of the parameters will be calibrated/estimated. First, a set of data targets is picked. These targets summarize the data along five dimensions: the time allocations for both married and single households, the fraction of the population married, the divorce rate, and the marriage rate. Second, the parameter values in question are then chosen to maximize the model's fit with respect to these data targets. Specifically, for this section, define $\tilde{d}_{t}^{j}$ to be the $j$ th data target for period $t$. Let $\lambda$ be the vector of parameters to be estimated. The model will yield a prediction for the 
$j$ th data target as a function of these parameters and time, denoted by $d_{t}^{j}=D^{j}(\lambda, t)$. The estimation procedure solves

$$
\min _{\lambda} \sum_{j=1}^{5}\left\{\sum_{t \in \mathcal{T}} I_{t}^{j} \omega_{t}^{j}\left[\tilde{d}_{t}^{j}-D^{j}(\lambda, t)\right]^{2} /\left(\sum_{t \in \mathcal{T}} I_{t}^{j}\right)\right\},
$$

where $\lambda \equiv\left(\mathbf{c}, p_{1950}, \gamma, \alpha, \zeta, \mu_{s}, \sigma_{s}, \mu_{m}, \sigma_{m}, \rho\right), I_{t}^{j} \in\{0,1\}$ is an indicator function returning a value of one if there is an observation at date $t, \omega_{t}^{j}$ gives the weight assigned to the target, and $\mathcal{T} \equiv\{1950,1960, \ldots, 2000\}$. Unlike the theory, the estimation does not restrict $\mathbf{c} \geq 0$ or $\zeta<0$; the data will decide the magnitudes and signs of these parameters.

It is interesting to compare this strategy for picking parameter values with the conventional one employed in business cycle analysis, discussed in Cooley and Prescott (1995). Business cycle analysis models short-run fluctuations around a stationary mean. Hence, parameter values are typically picked so that the model matches up with some relevant long-run averages from the data. In contrast, the current analysis focuses on long-run changes in a nonstationary world. The strong trends observed in the data speak to the degree of curvature in tastes and technologies. Thus, the information contained in these trends should be used to estimate parameter values. This is allowed by letting data targets at different points in time enter into (P5). A discussion of the 10 parameters to be estimated and the 16 data targets used to identify them will now follow.

Household technology parameters - time allocations. Obtaining a price series for purchased household inputs is somewhat problematic. So, a time path of the form $p_{t}=p_{1950} \times e^{-\gamma(t-1950)}$ will be estimated here, where $\gamma$ is the rate of decline in the time price for purchased household inputs and $p_{1950}$ is the initial price. The fixed cost for household maintenance, c, plays an important role in controlling the initial level of market work expended by singles relative to married households. Nothing is known about its value, so it will also have to be estimated. Thus, three household technology parameters will be estimated: c, $p_{1950}$, and $\gamma$.

To match the model up with the data on time allocations, note that the fraction of time spent by a married household on market work, $l^{m}$, is given by $l^{m}=\left(2-h^{m}\right) / 2$. Likewise, the fraction of time spent by a single household working in the market is $l^{s}=1-h^{s}$. Now, note that $l^{m}$ and $l^{s}$ can be written as functions of the parameters to be estimated, namely, $\mathbf{c}, p_{1950}$, and $\gamma$. They are also functions of time, $t$, and the taste parameters $\alpha$ and $\zeta$. Thus, write $l_{t}^{m}=L^{m}\left(\mathbf{c}, p_{1950}, \gamma, \alpha, \zeta ; t\right)$ and $l_{t}^{s}=L^{s}\left(\mathbf{c}, p_{1950}, \gamma, \alpha, \zeta ; t\right)$. 
Now, to operationalize the above in (P5), let $\tilde{d}_{t}^{1} \equiv \tilde{l}_{t}^{m}, D^{1}(\lambda, t) \equiv$ $L^{m}\left(\mathbf{c}, p_{1950}, \gamma, \alpha, \zeta ; t\right), \tilde{d}_{t}^{2} \equiv \tilde{i}_{t}^{s}$, and $D^{2}(\lambda, t) \equiv L^{s}\left(\mathbf{c}, p_{1950}, \gamma, \alpha, \zeta ; t\right)$ for $t=1950,1960, \ldots, 1990$. Also, set $\omega_{t}^{1} / 2$ and $\omega_{t}^{2} / 2$ to be the fractions of married and single females in the time $t$ population of women. (Note that $\omega_{t}^{1}+\omega_{t}^{2}=2$, the number of data targets for the time allocations.) The theory developed suggests that the parameters c, $p_{1950}$, and $\gamma$ will be important for determining the time paths for hours worked. As a practical matter, it turns out that the time paths for hours worked largely identify the magnitudes of $\mathbf{c}, p_{1950}$, and $\gamma$. Note that, as was mentioned earlier, the matching parameters, $\mu_{s}, \sigma_{s}, \mu_{m}, \sigma_{m}$, and $\rho$, do not even enter into the $L^{m}(\cdot)$ and $L^{s}(\cdot)$ functions.

Taste and matching parameters-vital statistics. There are seven taste and matching parameters that need to be estimated, namely, $\alpha, \zeta, \mu_{s}$, $\sigma_{s}, \mu_{m}, \sigma_{m}$, and $\rho$. The parameter $\alpha$ determines the weight of market goods in the utility function, and the parameter $\zeta$ controls the degree of concavity in the utility function for nonmarket goods. The more concave this utility function is, the faster households will move away from nonmarket goods toward market goods as income rises. Hence, this parameter plays an important role in determining how the relative benefits of married versus single life respond to technological progress. The idea here is that information on the trend in vital statistics is important for determining the value of $\zeta$. The remaining six matching parameters govern the noneconomic aspects of marriage. Again recall that $L^{m}(\cdot)$ and $L^{S}(\cdot)$ are not functions of the matching parameters.

These seven parameters impinge heavily on the model's predictions concerning vital statistics. Here, the data are targeted along three dimensions for two years, 1950 and 2000: the fraction of the population married, the divorce rate, and the marriage rate. So, let $\tilde{m}_{1950}^{j}$ and $\tilde{m}_{2000}^{j}$ denote the data targets along the $j$ th dimension for the years 1950 and 2000. Correspondingly, permit $m_{1950}^{j}=M^{j}\left(\mathbf{c}, p_{1950}, \gamma, \alpha, \zeta, \mu_{s}, \sigma_{s}\right.$, $\left.\mu_{m}, \sigma_{m}, \rho ; 1950\right)$ and $m_{2000}^{j}=M^{j}\left(\mathbf{c}, p_{1950}, \alpha, \zeta, \mu_{s}, \sigma_{s}, \mu_{m}, \sigma_{m}, \rho ; 2000\right)$ to represent the model's steady-state output along the $j$ th dimension for the years 1950 and 2000. Hence, in (P5) set $\tilde{d}_{t}^{j+2} \equiv \tilde{m}_{t}^{j}, D^{j+2}(\lambda, t) \equiv$ $M^{j}\left(\mathbf{c}, p_{1950}, \gamma, \alpha, \zeta, \mu_{s}, \sigma_{s}, \mu_{m}, \sigma_{m}, \rho ; t\right)$, and $\omega_{t}^{j+2}=1$, for $j=1,2,3$ and $t=1950$ and 2000. (Again, note that $\omega_{t}^{3}+\omega_{t}^{4}+\omega_{t}^{5}=3$, the number of data targets for the vital statistics.)

In summary, the parameter vector $\lambda \equiv\left(\mathbf{c}, p_{1950}, \gamma, \alpha, \zeta, \mu_{s}, \sigma_{s}, \mu_{m}\right.$, $\left.\sigma_{m}, \rho\right)$ is estimated so that the model matches the data on five dimensions: the time allocations for married households, the time allocations for single households, the fraction of the population married, the divorce rate, and the marriage rate. This involves 16 observations from 
the U.S. data. The estimation procedure employed is similar to one used by Andolfatto and MacDonald (1998). Given the paucity of observations, there is little point in adding an error structure to the estimation. Owing to the heavy time costs of simulating the full model, the parameter $\alpha$ was arbitrarily restricted to lie in a 21-point discrete set $\mathcal{A}=\{0.2, \ldots$, $0.278, \ldots, 0.4\}$. The parameter values obtained from the above procedure for matching the model with the data are presented in table 2. Before proceeding, note from table 2 that the estimation procedure chooses c $>0, \zeta<0$, and $\gamma>0$. Therefore, when the simple structure outlined is estimated, the data call for the presence of a fixed cost in household production, a utility function for nonmarket goods that is more concave than the one for market goods, and a declining time price for purchased household inputs; contrary to the theory, none of these features are imposed on the estimation procedure.

There is some indirect evidence, both cross-sectional and time-series, that there might indeed be stronger diminishing marginal utility in nonmarket goods vis-à-vis market goods. Households with higher incomes tend to allocate a larger share of their total food consumption for food away from home. According to the U.S. Bureau of Labor Statistics (2007, 7, table 1), in 2005 food away from home was about 35\% of total food consumption for households in the bottom income quintile, whereas the same share for those at the top income quintile was 50\%. During the last century, as incomes rose, the share of food, housing, and household operation in personal consumption expenditure fell. Such spending constituted about $56 \%$ of total expenditure in 1929, whereas it was about $40 \%$ of total expenditure in 2000 (from the U.S. National Income and Product Accounts).

Table 2

Parameter Values

\begin{tabular}{lll}
\hline Category & \multicolumn{1}{c}{ Parameter Values } & \multicolumn{1}{c}{ Criteria } \\
\hline Tastes & $\beta=0.960 \times(1-\delta), \phi=0.766$ & A priori information \\
& $\alpha=0.278, \zeta=-1.901$ & Estimated-vital statistics \\
Technology & $\mathrm{c}=0.131$ & Estimated-hours data \\
& $\theta=0.206, \kappa=0.189$ & A priori information \\
Life span & $1 / \delta=47$ & A priori information \\
Shocks & $\mu_{s}=-4.252, \sigma_{s}^{2}=8.063$ & Estimated-vital statistics \\
& $\mu_{m}=0.521, \sigma_{m}^{2}=0.680, \rho=0.896$ & \\
Prices & $p_{1950}=9.959, \gamma=0.059$ & Estimated-hours data \\
& $p_{t}=p_{1950} \times e^{-\gamma \times(t-1950)}$ for $t=1951, \ldots, 2000$ & \\
Wages & $w_{1950}=1.00 \quad$ Normalization \\
& $w_{t}=w_{1950} \times e^{0.022 \times(t-1950)}$ for $t=1951, \ldots, 2000$ & A priori information \\
\hline
\end{tabular}




\section{B. Results}

Visualize the economy in 1950. Wages are low and the price for purchased household inputs is high, at least relative to 2000. Over time, wages grow and the price for purchased household inputs falls. The time paths for wages and prices inputted into the analysis are shown in figure 4. As can be seen, in the U.S. data, wages increase 3.0 times over the time period in question. Prices are estimated to decline by a factor of 20. This seems large, but it is merely the result of compounding a $6.0 \%$ annual decline over a 50 -year period. Can these two facts help to explain the decline in marriage and the rise in divorce over the last 50 years? This is the question asked here.

\section{Household Hours}

The time path for household hours that arises from the model is shown in figure 5. It mimics the U.S. data reasonably well. In particular, the model matches very well the sharp increase in the fraction of time devoted to market work by married households. This is due to the declining price for purchased household inputs. Purchased household inputs and housework are substitutes in household production. As the price of

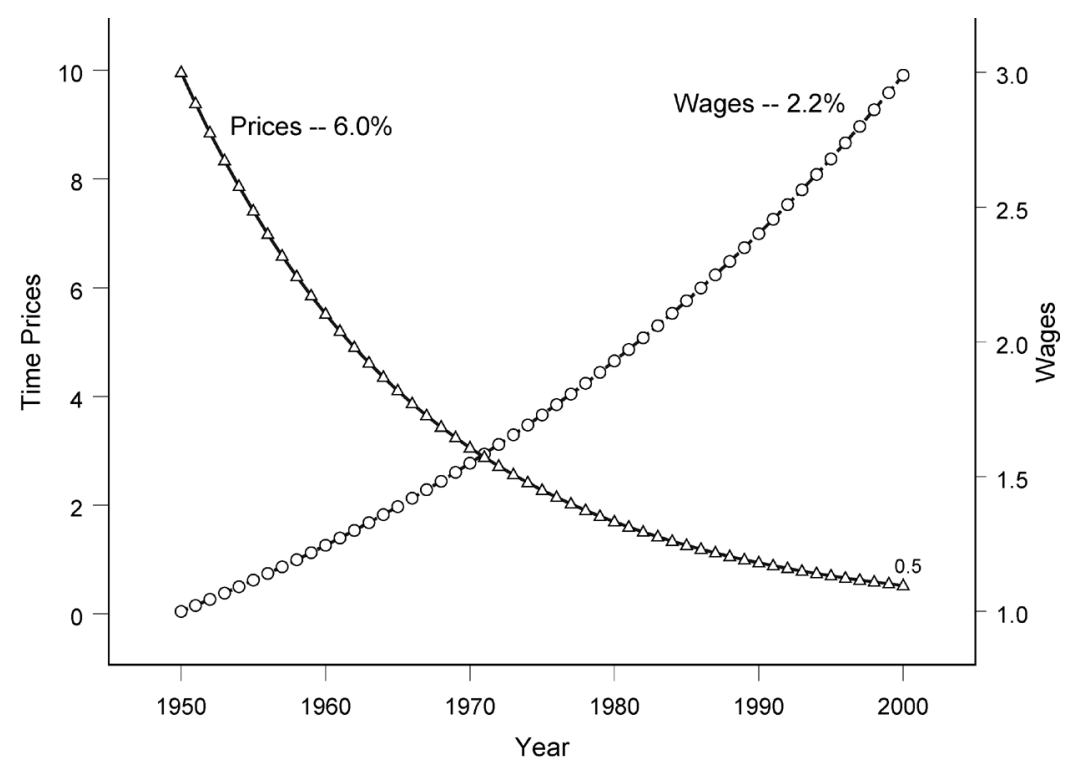

Fig. 4. Wages and prices, 1950-2000: model inputs 

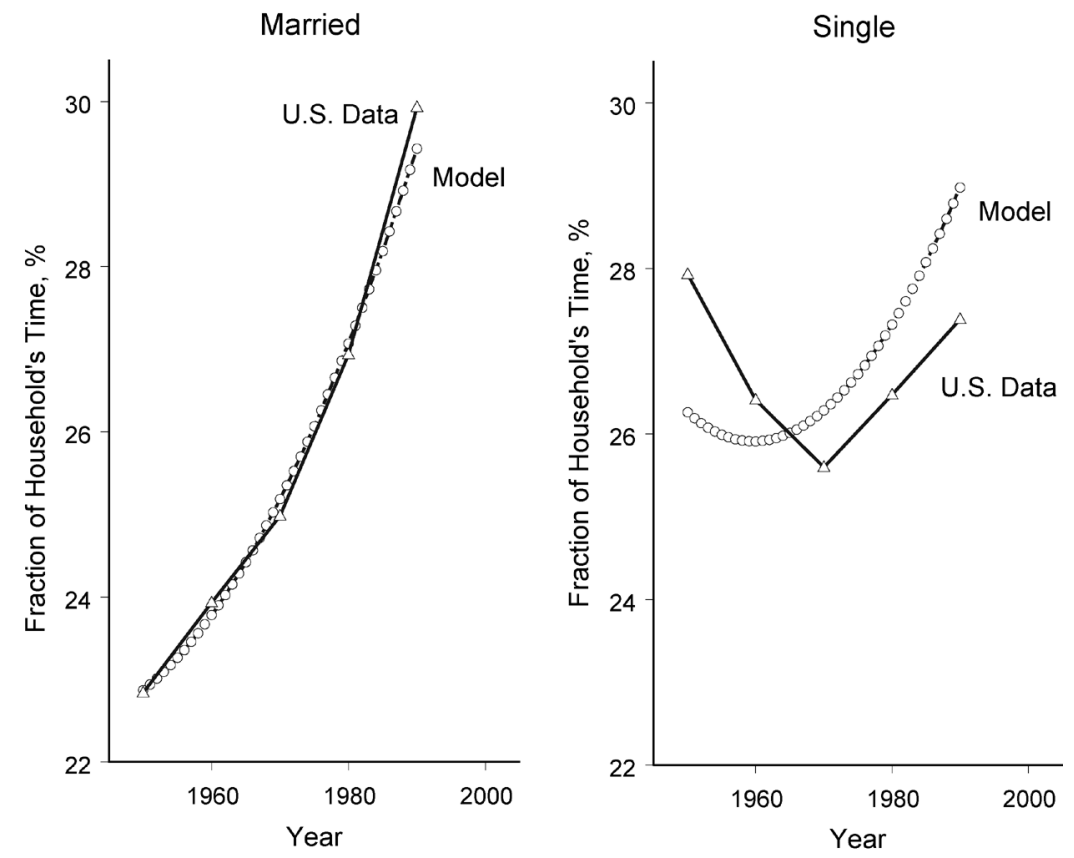

Fig. 5. Household hours, 1950-90: U.S. data and model

purchased household inputs declines, households substitute away from using labor at home toward using goods. The tight fit should not be seen as precluding the influence of other factors. For example, Albanesi and Olivetti (2006) argue that advances in obstetric and pediatric medicine and the introduction of new products such as infant formula also promoted labor force participation by married women.

The model has trouble mimicking the enigmatic U-shaped pattern for single households; still, note the presence of an attenuated U. It does a reasonable job of predicting the rise in participation from 1970 on. Observe that in 1950 married households devoted a smaller fraction of their time to market work than single ones, in both the data and the model. In the model this derives from the fixed cost of household maintenance. This forces low-income households to work more than high-income ones. In the model the low-income households are singles. As wages rise this effect disappears. By 1990 in the United States, married households worked more than single ones did. This is surprising since married households are much more likely to have children. In the model, they work about the same. Perhaps in the real world more productive individuals are also more desirable on the marriage market. Indeed, Cornwell 
and Rupert (1997) provide evidence that this is the case. Such a marriage selection effect is missing in the model.

The estimation procedure picks a $6.0 \%$ annual rate of price decline, as was mentioned. This looks reasonable. For instance, the Gordon qualityadjusted time price index for air conditioners, clothes dryers, dishwashers, microwaves, refrigerators, televisions, videocassette recorders, and washing machines fell at $10 \%$ a year over the postwar period. Alternatively, one could take the price of kitchen and other household appliances from the National Income and Product Accounts. This price series declined, relative to wage growth, at about $1.5 \%$ a year since 1950. The $6 \%$ estimate obtained here is the midpoint of these two numbers.

\section{Vital Statistics}

Now, the model starts off from an initial steady state that resembles the United States in 1950 and converges to a final one looking like the United States in 2000. In 1950 about $81.6 \%$ of the female population was married (out of nonwidows who were between the ages of 18 and 64). There were 10.6 divorces per 1,000 married females and 211 marriages. According to Schoen (1983), marriages lasted about 30 years in 1950. In 2000 the picture was quite different. Only $62.5 \%$ of females were married. The divorce rate had risen to 23 divorces by 1995, and the marriage rate had declined to about 80 marriages. Finally, the average duration of marriages was about $20-24$ years. ${ }^{7}$ Table 3 shows the model's performance along these dimensions. Note that singles face a distribution with a low mean and a high variance, whereas married people face a distribution that has a relatively high mean, a low variance, and a high autocorrelation (see table 2). This has two effects. First, it encourages singles to wait a while until a good match comes along. Second, it generates the long durations of marriages observed in the data.

Table 3

Initial and Final Steady States

\begin{tabular}{lccccc}
\hline & \multicolumn{2}{c}{1950} & & \multicolumn{2}{c}{2000} \\
\cline { 2 - 3 } \cline { 6 - 6 } & Model & Data & & Model & Data \\
\hline Fraction married & .816 & .816 & & .694 & .625 \\
Probability of divorce & .011 & .011 & & .024 & .023 \\
Probability of marriage & .129 & .211 & & .096 & .082 \\
Duration of marriages & 31.36 & 29.63 & & 22.47 & $20-24$ \\
\hline
\end{tabular}


The fraction of the population that is married declines with the passage of time in the model. Figure 6 compares results obtained from the model with the U.S. data. The model can explain 12 percentage points of the observed 19-percentage-point decline in the number of married females. This seems reasonable since other things went on in the world, such as a rise in the number of people going to college, a decline in fertility, and so forth. Observe that the utility differential between married and single life declines over time. ${ }^{8}$ This occurs for two reasons. First, recall that the utility function for nonmarket goods is more concave than the one for market goods. Thus, high-income households (married couples) spend less on household inputs relative to market consumption than low-income household (singles). As a consequence, a fall in the price of purchased household inputs has a bigger impact on singles vis-à-vis married couples. Second, as wages rise, the importance of the fixed cost for household maintenance disappears. This is more important for single households than for married ones. Finally, many couples choose to live together but not marry. The framework can be thought of as modeling couples living together. The fraction of females living with a male fell by 16 percentage points between 1960 and 2000. From this angle,
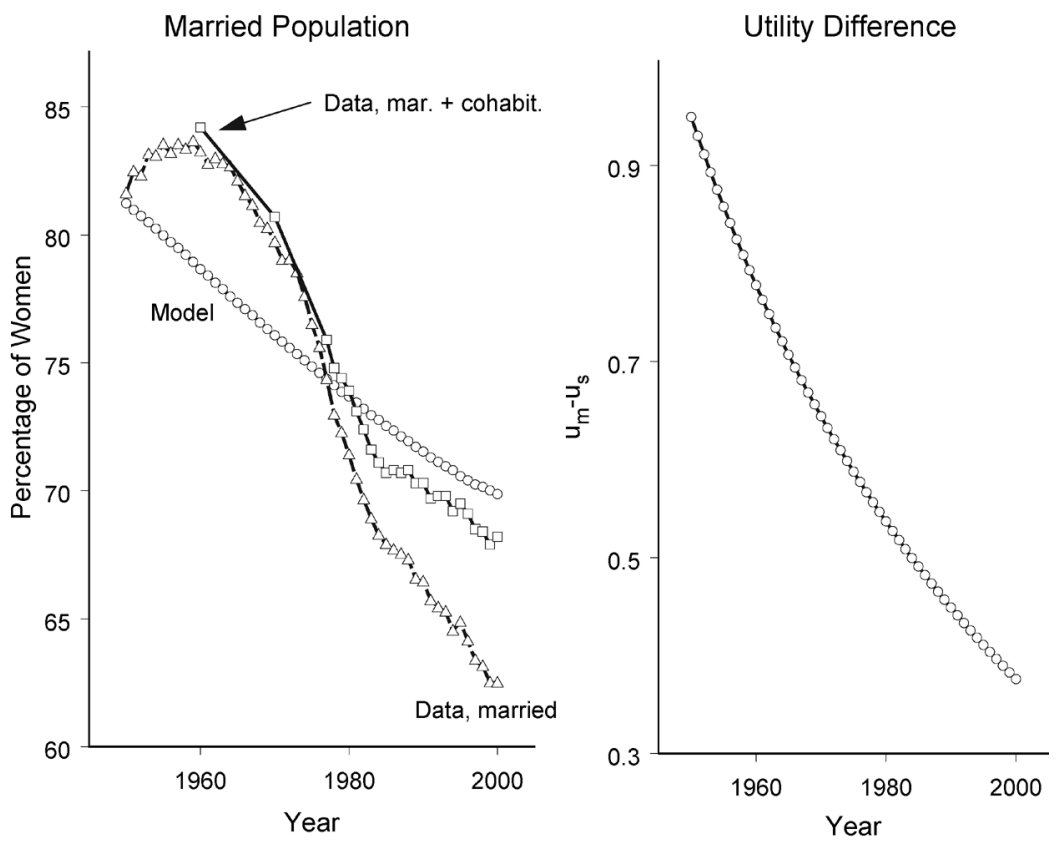

Fig. 6. Decline in marriage, 1950-2000: U.S. data and model 
the model captures about 75\% of the decline between 1950 and 2000 . Interestingly, the model seems to do well predicting the number of marriages for the first half of the sample and the number of cohabitations for the later half.

Underlying the decline in the fraction of the U.S. population that is married is a rise in the divorce rate and a decline in the rate of marriage. This is true for the model too, as can be seen in figure 7. In the model, divorces rise from 11 to 24 per 1,000 married women. This compares with 11 to 23 in the data. Marriages in the model fall from about 129 to 94 per 1,000 unmarried women. In the data they dropped from 141 to 69 or from 211 to 82 , depending on the measure preferred. Thus, by either measure, the drop in marriages in the model is a little anemic. Again, it is not surprising that the model does not do well in this regard. Some important factors have been left out, such as the rise in education that surely must be associated with the delay in first marriages or a narrowing in the gender gap that may have promoted female labor force participation and made single life a more desirable option for females. Finally, in the data the duration of a marriage was 30 years in 1950. By 2000 this had declined to roughly 22 years. The model does well in this
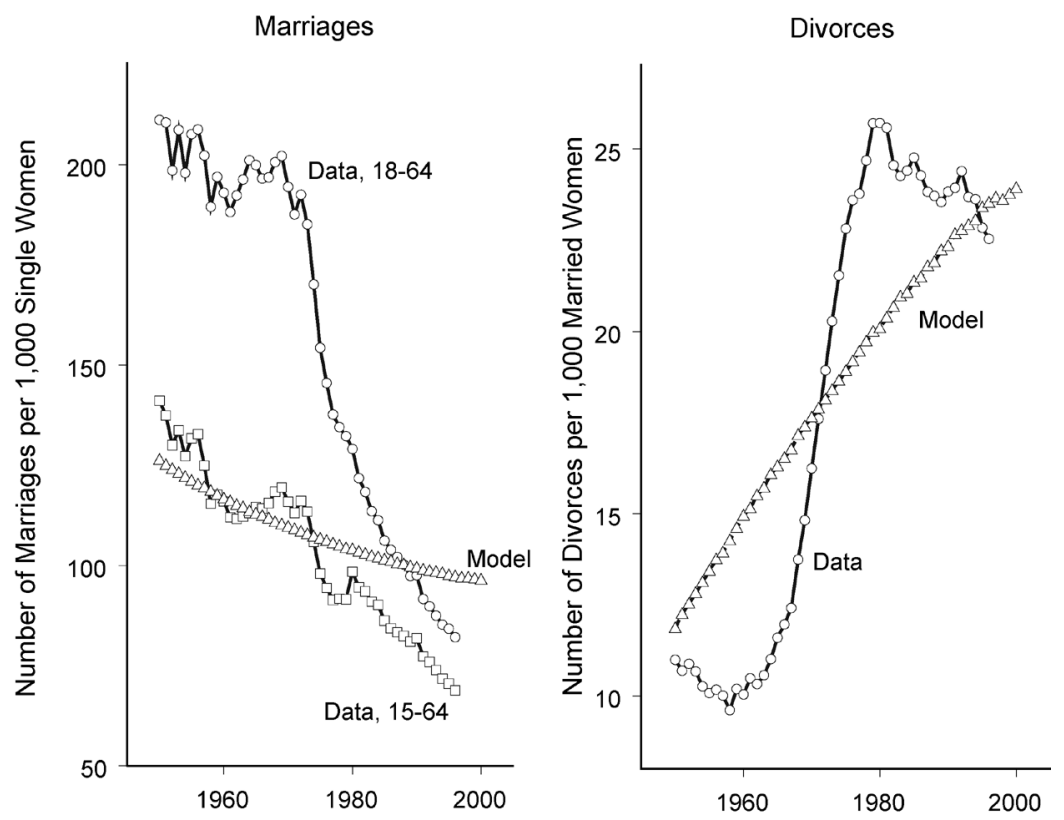

Fig. 7. Rates of marriage and divorce, 1950-96: U.S. data and model 
regard. It predicts that the duration of a marriage was 31 years in 1950 and 22 years in 2000 .

\section{1920-2000: A Proposed Extension}

The effects of technological progress on the formation of households were beginning to percolate before World War II. How are these effects manifested in the data? Can the model be modified to address them?

\section{A. The Marriage Data}

Figure 8 plots the proportion of the female population that was married from 1880 to 2000 . About $72 \%$ of the population was married in 1900, as opposed to $62 \%$ in 2000 . So, 10 percentage points fewer women were married at the end of the twentieth century relative to the beginning. Observe that the number of marriages shows a hump-shaped pattern roughly coinciding with the baby boom years. This pattern is not as dramatic as it seems at first glance, though. The population was much younger at the turn of the last century than it is today. Women aged 18-24 made up $28 \%$ of the population in 1900 . Now they account for $15 \%$. Young women are much less likely to be married than older ones. Figure 8 also shows the fraction of the female population that are married after

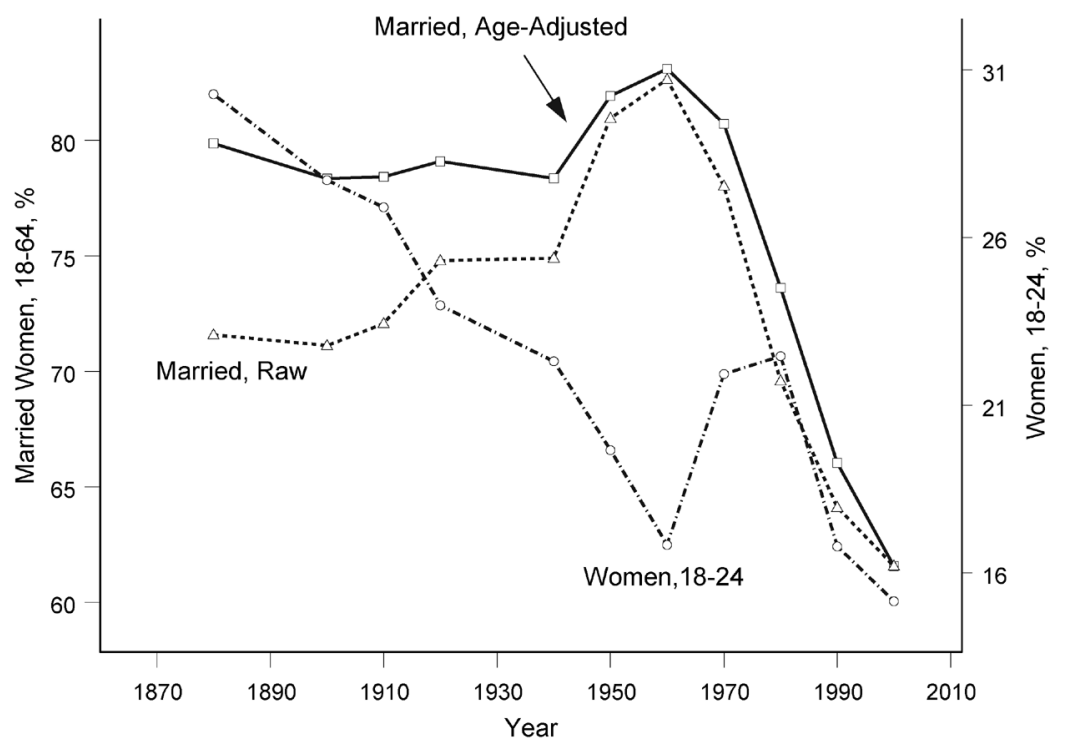

Fig. 8. Marriage, 1880-2000 
a correction is made for the shift in the age distribution. First, note that many more females were married at the beginning of the century than at the end, about 17 percentage points more. Second, the hump is still there, but it is much less pronounced. What can account for this hump-shaped pattern in marriage? Specifically, why did the number of marriages rise between 1940 and 1960 and subsequently decline?

\section{B. Living Arrangements of Young Adults}

At the beginning of the twentieth century the vast majority of nevermarried young females (close to $80 \%$ ) lived as dependents with their parents. A substantial fraction lived in households as nonrelatives, for example, boarders, servants, and so forth. Almost none lived in their own household, however. The fraction of young stand-alone households made up by singles has become much more prevalent over time. It has risen from close to zero at the turn of the last century to about $50 \%$ today, as figure 9 illustrates. Additionally, figure 9 plots the proportion of young households made up of married couples. As can be seen, it fell from nearly $100 \%$ at the turn of the last century to less than $50 \%$ today. Interestingly, this plot shows a monotonic decline from roughly 1920 on; the hump has disappeared.

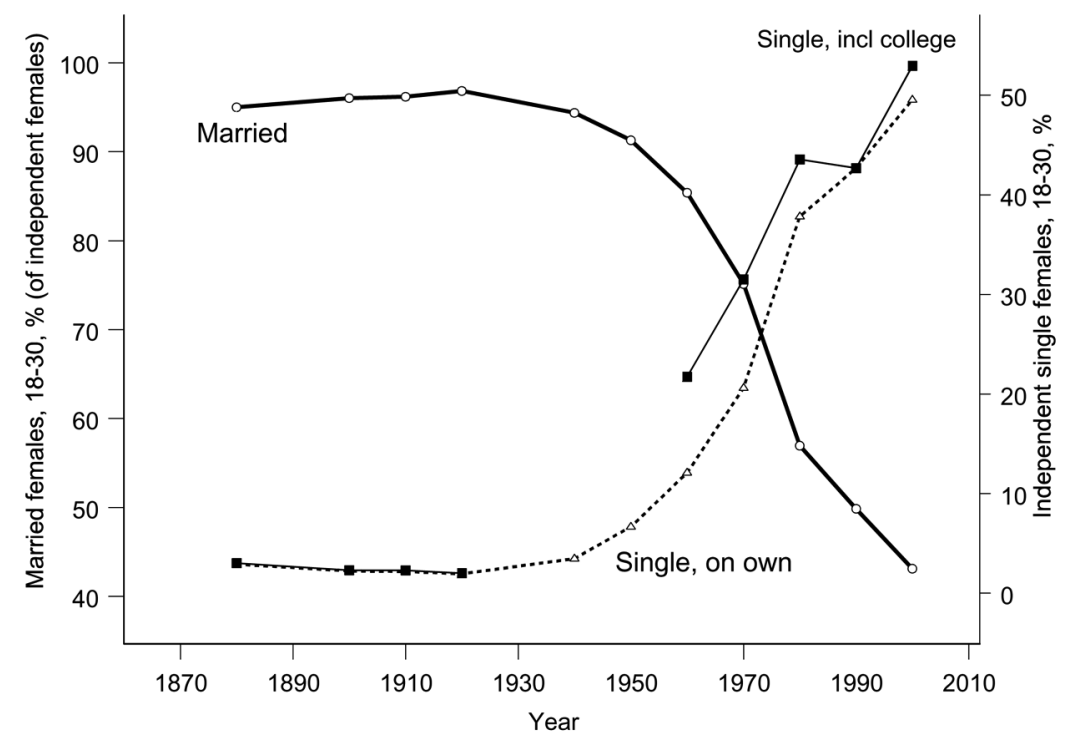

Fig. 9. Living arrangements for young women, 1880-2000 


\section{Returning to the Hypothesis}

The idea here is that technological progress in the household sector made it feasible to establish smaller and smaller households. In the initial stages of development, technological advance made it easier for a young adult to leave his or her parents' home and marry. As household technology progressed further, it became viable for young adults to leave home and remain single. Therefore, the move by young adults from large to two-person households coincided with an increase in marriages whereas the subsequent shift toward one-person households was associated with a decline. This hypothesis is consistent with the decline in the fraction of total young households made up of married ones that was shown in figure 9.

\section{Altering the Setup}

To gauge whether or not this hypothesis has promise, consider the following simple extension of the model. Let there now be three types of individuals: singles living at home with their families (dubbed young adults), singles living in their own homes, and married couples living in their own households. Suppose that a young adult living with his family receives a momentary utility of $H-x$. Here $H$ gives the economic benefit from living at home, as a function of the underlying state of the economy $(w, p)$. The variable $x$ represents the psychic disutility from living at home (vs. alone), so to speak. Each single starts adulthood living at home with his or her parents and sibling. Assume that a young adult first leaves home single and then looks for a mate. In particular, he or she exits the family nest with probability $\varepsilon$. This probability is a choice variable, which is dependent on the amount of effort that the youngster invests in leaving home. Let the convex cost function for leaving home, $C:[0,1] \rightarrow R_{+}$, be specified by

$$
C(\varepsilon)=\iota \frac{\varepsilon^{1+\chi}}{1+\chi} \quad \text { for } \chi>0 .
$$

Once departed, the youngster can never return. Also, presume that a family realizes no benefit (or incurs a cost) from a child staying at home. The rest of the setup remains the same as before. The analysis will focus on steady states. 
Let $Y$ be the expected lifetime utility for a young adult who is currently living at home. His dynamic programming problem is given by

$$
Y=H-x+\beta \max _{0 \leq \varepsilon \leq 1}\left\{\varepsilon \int \max [V(b), W] d S(b)+(1-\varepsilon) Y-C(\varepsilon)\right\} .
$$

The solution for $\varepsilon$ is given by

$$
\varepsilon=\left\{\frac{\int \max [V(b), W] d S(b)-Y}{\iota}\right\}^{1 / x} \text { for } 0 \leq \int \max [V(b), W] d S(b)-Y \leq \iota .
$$

As can be seen, a youngster will be more diligent about leaving home when the gains from entering the singles market, $\int \max [V(b), W] d S(b)$, are high relative to the benefits of staying at home, $Y$. Now, consider an increase in wages or a fall in prices. These will lead to reductions in the number of young adults living at home, as long as the benefits of independent single life rise more than the benefits of a dependent one, that is, as long as $\partial \int \max [V(b), W] d S(b) / \partial w>\partial Y / \partial w$ or $\partial \int \max [V(b)$, $W] d S(b) / \partial p<\partial Y / \partial p$. The considerations ensuring this parallel those outlined in Section V.

Note that problems (P1) and (P2) remain the same as before, since the decision to leave home is irreversible and because a married couple realizes no utility from a child living at home. In a steady state the equation specifying the type distribution for marriages will appear as

$$
\begin{aligned}
\mathbf{M}(b)= & (1-\delta) \iint_{\mathcal{M} \cap[-\infty, b]} d M\left(\tilde{b} \mid b_{-1}\right) d \mathbf{M}\left(b_{-1}\right) \\
& +[(1-\delta) S+(1-\delta) \varepsilon y+\delta \varepsilon] \int_{\mathcal{M} \cap[-\infty, b]} d S(\tilde{b}),
\end{aligned}
$$

where the number of young adults living at home with their parents, $y$, is given by

$$
y=\frac{\delta(1-\varepsilon)}{1-(1-\delta)(1-\varepsilon)}
$$

and

$$
\int d \mathbf{M}(b)+s+y=1
$$

(cf. [5]). Therefore, a huge virtue of this setup is that it involves little modification to the original formulation. 


\section{An Example}

Does the above setup have promise for extending the earlier analysis to the pre-World War II period? To address this question, the model's potential will be demonstrated using a simple example. The example will focus on three years, to wit, 1920, 1950, and 2000. For each year the model's steady state will be computed. The output from the model will then be compared with the stylized facts discussed in Sections VII.A and B. It should be emphasized that given the simplicity of the setup, the example is intended only as an illustration; it should not be viewed as a serious data-fitting exercise.

For the taste and technological parameters, take the values presented in table 2 with two changes. Presumably the price for purchased household inputs fell faster earlier in the last century than later on. So allow the price to fall at the constant rate $\gamma_{1920}$ prior to 1950. Additionally, the fixed cost for household formation will be allowed to differ for this subperiod as well. Denote this by $\mathbf{c}_{1920}$. The above setup changes the pool of singles that are available on the marriage market. So, new matching parameters will be selected. These values will apply for the whole 1920-2000 period. Something must be specified for the economic benefit that a young adult derives from staying at home with his parents, $H(w, p)$. Simply suppose that each family has two kids and set $H(w, p)=$ $I(4, p, w)$. That is, each period a young adult who stays at home realizes the maximal level of momentary utility that would arise in a household with four wage earners. (One could just as easily set $H(w, p)=\vartheta I(4, p$, $w)$ for some $\vartheta \in(0,1)$. The essential requirement is that the economic benefit of living in a large household should decline over time relative to a small one.) Given the primitive nature of the example, the parameter values are selected so that the model's steady states display some features of interest, discussed below. The parameter values selected are presented in table 4.

In the model, $63.8 \%$ of single women work in 1920 , the same number as in the data for women between the ages of 18 and 64 (see table 5).

\section{Table 4}

New Parameter Values: Example

\begin{tabular}{ll}
\hline Household production & $\mathrm{c}_{1920}=0.161, \gamma_{1920}=0.165$ \\
Shocks & $\mu_{s}=-3.75, \sigma_{s}^{2}=8$ \\
& $\mu_{m}=0.145, \sigma_{m}^{2}=0.28, \rho=0.59$ \\
Utility of living at home & $H(w, p)=I(4, p, w)$ \\
& $x=2.051$ \\
Utility cost of leaving home & $\iota=115.27, x=1.083$ \\
\hline
\end{tabular}


Table 5

Participation Rates, 1920

\begin{tabular}{lcc}
\hline & Model & Data \\
\hline Married & .078 & .078 \\
Single & .638 & .638 \\
\hline
\end{tabular}

Likewise, only $7.8 \%$ of married women work in 1920, again the same as is observed in the data. By construction, the model still generates the hours-worked predictions shown in figure 5 for the period 1950-90. This transpires because the hours-worked decisions are functions solely of the taste and technology parameters, and these have not been changed for the 1950-2000 period. Table 6 presents the results for some vital statistics. The statistics for the U.S. data apply to women in the 18-64 age group (as in table 3). The numbers have also been adjusted for the shift in U.S. age distribution, which was discussed earlier. First, as can be seen, the model replicates quite nicely the stylized facts for the fraction of females who are married. In particular, the model duplicates the humpshaped pattern displayed in the data. An improvement in fitting the numbers for 2000 can be obtained at the sacrifice of a diminution in the left-hand side of the hump. Second, it also does a reasonable job of predicting the decline in the proportion of single females who live at home with their parents. Third, analogously, it mimics well the rise in the fraction of single females who live alone. Fourth, the number of adults living in a household declined monotonically over the course of the last century, as table 6 shows. This is true for the model as well. The model cannot match the steepness of this decline. One reason might be that fertility declined in the United States over this time period, and the population aged significantly. The elderly are much more likely to live alone now, relative to the past. The model, of course, assumes that each woman always gives birth to two children. All in all, it looks as though an extension of the framework that models the decision of a young adult to leave home

Table 6

Household Living Arrangements

\begin{tabular}{|c|c|c|c|c|c|c|}
\hline & \multicolumn{2}{|c|}{1920} & \multicolumn{2}{|c|}{1950} & \multicolumn{2}{|c|}{2000} \\
\hline & Model & Data & Model & Data & Model & Data \\
\hline Married: $m$ & .796 & .791 & .819 & .819 & .680 & .616 \\
\hline Single, living at home: $y$ & 185 & .185 & .125 & .125 & .109 & .109 \\
\hline Single, living alone: $s$ & .019 & .024 & .056 & .056 & .212 & .275 \\
\hline Household size: number of adults & 2.40 & 2.55 & 2.15 & 2.14 & 1.81 & 1.65 \\
\hline
\end{tabular}


has promise for explaining the trends in vital statistics that are observed in the U.S. data.

\section{Discussion}

The proposed extension of the benchmark model is minimalist, to say the least. It is easy to identify areas of the analysis that warrant further work. At the heart of the above extension is a young adult's decision to leave home. Perhaps one could allow for a young adult to search for a mate while at home. Three options would then arise: stay at home, leave home married, and leave home single. Doing this will be important for matching the rates of marriage that are observed in the data. In the earlier part of the last century most females got engaged before they left home. Therefore, the model cannot hope to match the observed rates of marriage at early dates if marriageability is restricted to the small pool of single females living alone. Additionally, should searching for a mate while living in your parents' home be as efficient as searching for one when you live alone? Modeling the utility that a young adult receives while at home is another area in which the framework could be improved. Do transfers flow from young adults to parents or vice versa? The answer to this will depend on how parents care about their kids, how children feel about their parents, and their mode of interaction.

The economic forces that reduce the relative benefit of single versus married life may also have affected other living arrangements, such as the incentives of the elderly to live with their kids. Between 1970 and 1990 the fraction of widows living alone rose from $52.1 \%$ to $64.2 \%$. Bethencourt and Rios-Rull (2009) argue that the rise in the relative income of elderly widows can account for a significant part of the rise in the number of elderly widows living alone between 1970 and 1990. In a similar vein, Schoellman and Tertilt (2007) argue that a substantial proportion of the decline in household size is due to an increased demand for privacy, made possible by rising living standards.

\section{Some Cross-Country Evidence on Household Size}

The above theory suggests that as the relative price of purchased household inputs declines, so should the number of adults living in a household. The relationship between household size and price is displayed in the upper panel of figure 10 for a small sample of Western countries for the year 2001. As can be seen, there is a positive association between these two variables. Of course, other things may affect household size in a 

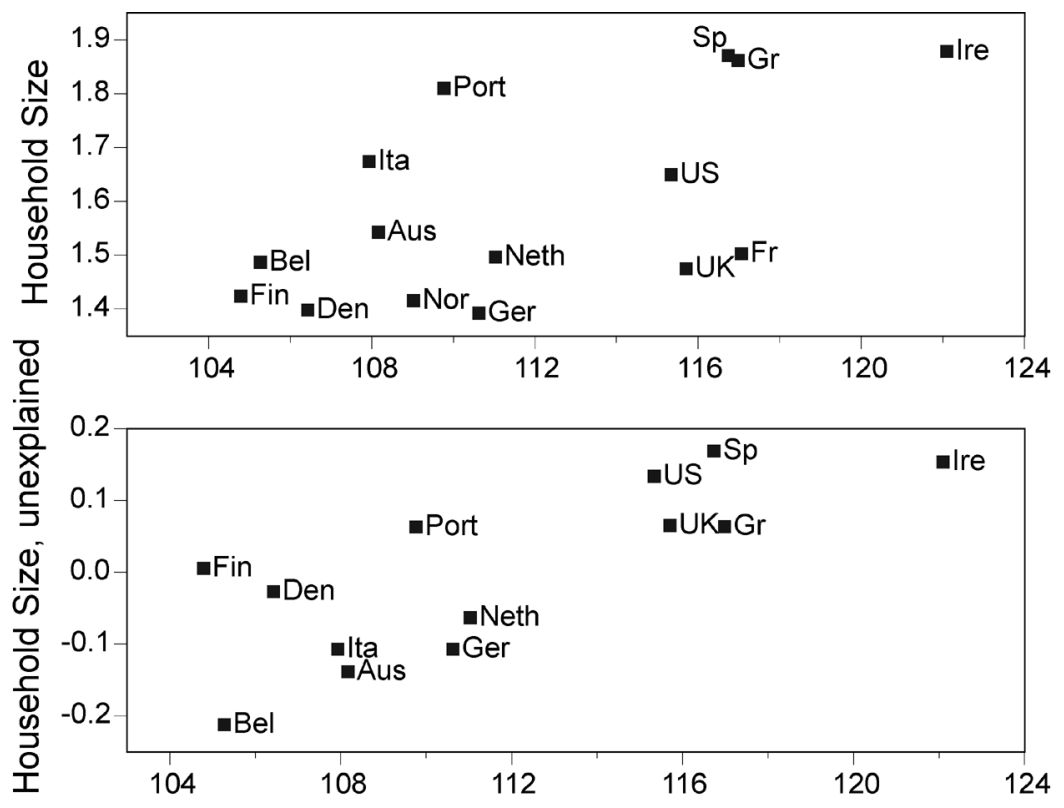

Relative Price of Household Appliances

Fig. 10. Cross-country relationship between household size and the relative price of appliances, 2001.

country. To take into account such factors, a linear regression of the following form is estimated:

$$
\mathrm{SIZE}=\mathrm{CONSTANT}+\beta \times \mathrm{PRICE}+\gamma \times \mathrm{CONTROLS}+\varepsilon,
$$

with $\varepsilon \sim N(0, \sigma)$, where CONTROLS represents a vector of control variables. A list of potential control variables might include GDP per capita, the gender gap, the extent of urbanization, the amount of product market regulation, and the religiosity of a population. The empirical analysis is in the spirit of Cavalcanti and Tavares (2008) and Algan and Cahuc (2007), who examined, using a panel of countries, the impact of appliance prices on female labor supply and younger and older (non-prime-age) workers, respectively. Theory suggests that $\beta$ should be positive. The size of this coefficient is also of interest because it indicates the power of the relative price effect.

The results of the analysis are presented in table 7 . They should be interpreted with the utmost caution because the sample size is so small. Focus attention on regression 5 . All the variables are statistically significant and enter in with the expected sign. The price effect in the regression is highly significant. One would expect, as per capita GDP rises, that 
Table 7

Cross-Country Regression Analysis

\begin{tabular}{lccccc}
\hline & \multicolumn{5}{c}{ Regression } \\
\cline { 2 - 6 } Independent Variable & 1 & 2 & 3 & 4 & 5 \\
\hline Constant & $-1.907^{* * *}$ & -1.699 & -.878 & $-2.110^{* * *}$ & $-1.092^{* * *}$ \\
& $(.545)$ & $(.466)$ & $(.513)$ & $(.434)$ & $(.331)$ \\
Relative price & $.0263^{* * *}$ & $.0275^{* * *}$ & $.0212^{* * *}$ & $.0267^{* * *}$ & $.0244^{* * *}$ \\
GDP per capita & $(.0047)$ & $(.0043)$ & $(.0040)$ & $(.0037)$ & $(.0033)$ \\
& & $-.000015^{* * *}$ & & & $-.000013^{* *}$ \\
Gender gap & & $(4.58 \mathrm{e}-06)$ & & & $\left(4.13 \mathrm{e}^{* 0.6)}\right.$ \\
Product market regulation & & & $-.637^{* *}$ & & $-.404^{* *}$ \\
& & & $(.233)$ & $.102^{*}$ & $(.135)$ \\
Religion & $.825^{* * *}$ & $.867^{* * *}$ & $.657^{* * *}$ & $(.049)$ & $.759^{* * *}$ \\
Observations & $(.165)$ & $(.109)$ & $(.189)$ & $(.196)$ & $.722^{* * *}$ \\
Adjusted $R^{2}$ & 14 & 14 & 14 & 14 & 13 \\
\hline
\end{tabular}

Note: Standard errors reflect Eicker-White correction for heteroscedasticity.

* Significant at $10 \%$. ${ }^{* *}$ Significant at $5 \% .{ }^{* * *}$ Significant at $1 \%$.

household size - the number of adults between ages 18 and 64-declines. Females will be less inclined to marry and more inclined to divorce, the higher their wage rate relative to males, since this makes it more likely that they can live an independent life. Indeed, in the regression, household size is negatively related to the gender gap, defined as the ratio of female to male wages. Religious societies may frown on young adults living by themselves or couples getting divorced. Household size is positively associated with religiosity, as measured by the fraction of the population that view themselves as religious. Other variables such as the fraction of the population that lives in urban areas (not shown), perhaps a measure of less traditional attitudes, or the degree of product market regulation, which increases the cost of living, have the expected signs but are less significant (when GPD per capita and the gender gap are included in the regression). Adding them changes only marginally the coefficient on the price effect or its significance. A robustness check found that controlling for the age structure of the population does not seem to matter much either. Additionally, the basic results continue to hold in a larger sample that includes ex-communist countries, such as Bulgaria, the Czech Republic, Estonia, and so forth. The lower panel in figure 10 shows the relationship between price and household size after controlling for the factors included in regression 5 .

What about the economic significance of the size of the coefficient on price in the regression? To gauge this, compare Finland, which had the 
lowest relative price level of 104.8, with Ireland, which had the highest relative price level of 122.01 . The relative price difference is associated with about 0.44 member per household (about $100 \%$ of the observed difference, from 1.424 for Finland to 1.879 for Ireland). This price effect is quantitatively powerful. An increase in per capita GDP from $\$ 17,440$ (Greece with a household size of 1.86) to $\$ 34,320$ (the United States with a household size of 1.65) leads to a drop in household size of 0.22 member (again almost all of the difference between the two countries). By comparison, the gender gap has a much weaker impact. Suppose that the gender gap shrinks from 0.4 (Ireland, the widest) to 0.7 (Denmark, the narrowest). Household size falls by 0.12 member, which represents $25 \%$ of the difference. Thus, the forces stressed in the paper appear to have a strong impact on household size.

\section{Conclusions}

The fraction of adult females who are married has dropped by roughly 20 percentage points since World War II. Females now spend a much smaller part of their adult life married than 50 years ago. Associated with this has been a rise in the divorce rate and a decline in the rate of marriage. At the same time, hours worked by married households rose considerably. This was driven by a large increase in labor force participation by married females.

An explanation of these facts is offered here. The story told focuses on technological progress in both the household and market sectors. The idea is that investment-specific technological progress in the household sector reduced the need to use labor at home. This simultaneously allowed women to enter the labor force and eroded the economic incentives for marriage. The analysis blends together a search model of marriage and divorce with a model of household production. The economic incentives for marriage derive from economies of scale in household production. These are whittled away over time for two reasons. First, rising wages make it easier to meet or exceed the fixed cost for household maintenance. This reduces the need to marry to make ends meet. Second, a falling price for laborsaving household inputs has a bigger impact on single vis-à-vis married households, since the former devote a larger share of their spending to these products as a result of a high rate of diminishing marginal utility for nonmarket consumption. These two effects increase the (relative) value of single life.

So, where can the analysis go from here? Technological progress in the home and market may affect the pattern of matching in society. 
There is some evidence that the degree of assortative mating in the United States has increased since 1940. ${ }^{9}$ Extensions of the model may be able to capture this. Suppose that individuals differ in their labor market productivities. Assume that married males devote all their time to market work whereas married females split their time between market work and household work. Now, when they choose a potential mate, their earnings in the labor market will be a consideration. This will matter less at early stages of economic development, since married women will do little market work because of the large amount of time spent in household production. As women start to work more in the market, owing to technological progress, it will begin to matter more. As an economy advances and the benefits from economies of scale in household consumption diminish, earnings potential along with marital bliss will become more important criteria when choosing a mate. The degree of assortative mating will increase. Additionally, such an analysis would likely imply that the drop in the marriage rate should be biggest for those individuals in lower-income groups, since the relative benefits from marriage will fall the most for them. Indeed, there is some evidence suggesting that this has been the case. ${ }^{10}$

\section{Appendix}

\section{A. Proofs}

As a prelude to the proofs of the lemmas and propositions, combine (7) and (8) to obtain

$$
d=\left[\frac{(1-\theta) p}{\theta}\right]^{1 /(\kappa-1)} h \equiv R(p) h .
$$

Using this in (6) then gives

$$
c-\mathbf{c}=w\left[\left(z-\frac{\mathbf{c}}{w}\right)-h\right]-w p d=w\left[\left(z-\frac{\mathbf{c}}{w}\right)-h\right]-w p R(p) h .
$$

Finally, by substituting (A1) and (A2) into (8), a single equation can be obtained in one unknown, namely $h$ :

$\alpha\left[\theta R(p)^{\kappa}+(1-\theta)\right]^{1-\zeta / \kappa} h^{1-\zeta}=(1-\alpha)(1-\theta) z^{-\phi \zeta}\left[\left(z-\frac{\mathbf{c}}{w}\right)-h-p R(p) h\right]$. 


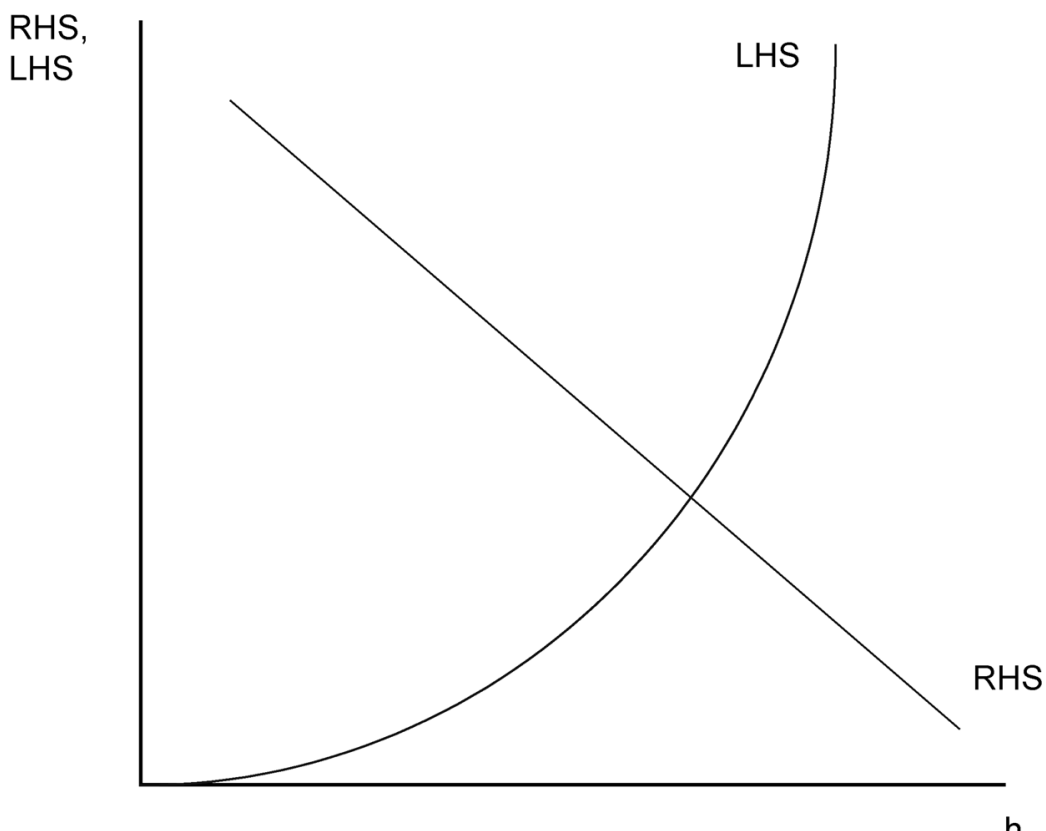

Fig. A1. Determination of $h$

The solution is portrayed in figure A1. It is easy to deduce that the lefthand side of (A3) is increasing in $h$ since $\zeta<0$. It is trivial to see that the right-hand side is decreasing in $h$.

Proof of proposition 1. On part $\mathrm{i}$, observe that both $R(p)=\{[(1-$ $\theta) / \theta] p\}^{1 /(\kappa-1)}$ and $p R(p)$ are decreasing in $p$ since $0<\kappa<1$. Therefore, the right-hand side of (A3) falls with a drop in $p$, as $-p R(p)$ is increasing in $p$. Thus, the RHS curve in figure A1 will shift down when $p$ declines. The left-hand side increases with a reduction in $p$ because $R(p)^{\kappa}$ is decreasing in $p$. Hence, the LHS curve shifts up. As a consequence, $h$ unambiguously drops. For parts ii and iii, note that $w$ and center into (A3) only in the form $\mathbf{c} / w$. It is trivial to see that the right-hand side of (A3) is decreasing in $\mathbf{c} / w$, whereas the left-hand side is not a function of $\mathbf{c} / w$. Therefore, an increase in $\mathbf{c} / w$ will cause $h$ to fall. The desired results follow immediately. QED

What is the relationship between the size of a household, on the one hand, and the amount of time allocated to housework and spending on goods, on the other hand? One would expect housework, $h$, to rise when size, $z$, increases because the total endowment of time has risen. This is true. A more interesting question is whether or not housework rises by a factor more or less than the proportionate increase in household 
size. On the one hand, given that the utility function for nonmarket goods is more concave than the one for market goods, the household has a preference for diverting extra resources into market consumption. This suggests that housework will increase less than proportionately with size. On the other hand, at higher levels of income the fixed cost for household maintenance will matter less. This suggests that housework will rise more than proportionately with size. While the result turns out to be ambiguous, a useful upper bound on the response of housework to household size can be derived. This is presented in lemma 3, which is an important step toward proving proposition 2. With this upper bound, it can be shown that married households spend less than single households do on the inputs into household production, $d$ and $h$, at least relative to market consumption, $c-\mathbf{c}$.

Lemma 3. A rise in $z$ by a factor of $\lambda>1$ leads to an increase in $h$ by a factor strictly less than $\rho=(\lambda z-\mathbf{c} / w) /(z-\mathbf{c} / w)$. When $\zeta=0$ (ln utility for nonmarket goods), a magnification in $z$ by a factor of $\lambda>1$ will cause $h$ to expand by exactly a factor of $\rho$.

Proof. Rewrite equation (A3) as

$$
\begin{gathered}
\alpha\left[\theta R(p)^{\kappa}+(1-\theta)\right]^{1-\zeta / \kappa} h^{-\zeta} h+(1-\alpha)(1-\theta)[1+p R(p)] z^{-\phi \zeta} h= \\
(1-\alpha)(1-\theta) z^{-\phi \zeta}(z-\mathbf{c} / w) .
\end{gathered}
$$

If $z$ increases by a factor $\lambda>1$, then $z-\mathbf{c} / w$ rises by the factor $\rho \equiv$ $(\lambda z-\mathbf{c} / w) /(z-\mathbf{c} / w)>\lambda$. Now, the right-hand side rises by the factor $\lambda^{-\phi \zeta} \rho$. Observe that if $h$ rises by the factor $\rho$, then the left-hand side will increase by more than the factor $\lambda^{-\phi \zeta} \rho$, because $\rho^{-\zeta}>\lambda^{-\phi \zeta}$ when $\zeta<0$ and $0<\phi<1$. Therefore, to restore equality between the left-hand and right-hand sides of the above equation, $h$ must rise by less than the factor $\rho$. The first part of the lemma has been established. Finally, suppose that $\zeta=0$. In this case, (A3) reduces to

$$
h=\frac{(1-\alpha)(1-\theta)(z-\mathbf{c} / w)}{\alpha\left[\theta R(p)^{\kappa}+(1-\theta)\right]+(1-\alpha)(1-\theta)[1+p R(p)]} .
$$

The second part of the lemma follows immediately. QED

In line with the intuition presented above on the relationship between household size and allocations, suppose that $\mathbf{c}=0$. In this case, $\rho=\lambda$. Thus, larger households will devote proportionately less of their time to housework than smaller ones, since an increase in household size by a factor $\lambda>1$ will lead to a rise in $h$ by a factor less than $\rho=\lambda$. Next, suppose that $\zeta=0$ and $\mathbf{c}>0$, so that both market goods and nonmarket 
goods have $\ln$ utility. If $z$ increases by a factor of $\lambda$, then $h$ will rise by exactly the factor $(\lambda z-\mathbf{c} / w) /(z-\mathbf{c} / w)>\lambda$. Now, larger households spend proportionately more of their time on housework relative to smaller ones. This lemma will now be used in the proof of lemma 1.

Proof of lemma 1. First, result iii is immediate from lemma 3. Second, it is easy to see that result ii is implied by equation (A1) and result iii. By using results ii and iii, in conjunction with equation (A2), one can obtain result i. Finally, the situation for $\zeta=0$ is readily handled by using the closed-form solution (A4). QED

Proof of corollary. From lemma 1, note that when $\zeta \leq 0$, it transpires that $\left(c^{m}-\mathbf{c}\right) \geq 2\left(c^{s}-\mathbf{c}\right)$, since $(2-\mathbf{c} / w) /(1-\mathbf{c} / w) \geq 2$. Thus, $\left(c^{m}-\mathbf{c}\right) /$ $2^{\phi} \geq 2^{1-\phi}\left(c^{\mathcal{s}}-\mathbf{c}\right)>c^{\mathcal{s}}-$ c. Part ii of the corollary follows trivially. QED

\section{B. Data}

Figure 1. The marital status of the population is reported in the U.S. Census Bureau publications Marital Status and Living Arrangements (March 1950 to March 1998) and America's Families and Living Arrangements (March 1999 to March 2000). The fraction of time spent married is calculated as follows: First, data on life expectancy, $e$, and the fractions of total life spent as never married, $n$, married, $m$, and divorced, $d$, are collected from Schoen (1983) and Schoen and Standish (2001). These data cover each year between 1950 and 1980 and the years 1983, 1988, and 1995. Second, on the basis of these numbers, the figures presented are then calculated as

$$
\frac{e \times m}{e \times n-18+e \times m+e \times d} .
$$

Figure 2. The divorce and marriage rates are contained in Clarke (1995a, 1995b). A caveat is in order. Whereas data are available on the number of unmarried women by age group, they are not available for marriages by age group. Hence, the marriage rate for a particular age group is computed as the total number of marriages divided by the total number of unmarried women in the given age group. Therefore, the marriage rates are somewhat sensitive to the particular age group used as the base for the calculations. Divorce and marriage statistics (which primarily come from the National Center for Health Statistics) are not available after 1996.

Figures 3 and 5. Simple tabulations are computed on the basis of U.S. Census data extracted from IPUMS-USA (Integrated Public Use Microdata Series, Minnesota Population Center, University of Minnesota). To 
calculate the fraction of time spent working in the United States for the period 1950-90, assume that there are 112 nonsleeping hours in a week. Following the footsteps of McGrattan and Rogerson (1998), weekly hours per married and single households can be calculated using U.S. Census data. For each decennial year between 1950 and 1990, the census provides hours per week in the following intervals: 1-14, 15-29, 30-34, $35-39,40,41-48,49-59$, and more than 60 hours. Let $E_{i}$ denote the number of people who report hours in a particular interval $i, E_{R}$ represent the total number of people reporting hours, $E$ stand for the total number of people employed, and $N$ be the total population. Then, the fraction of total nonsleeping time allocated to the market is calculated as

$$
\begin{gathered}
\left(7.5 E_{1-14}+22 E_{15-29}+32 E_{30-34}+37 E_{35-39}+40 E_{40}+44.5 E_{41-48}+42 E_{49-59}\right. \\
\left.+62.5 E_{60+}\right) \frac{1}{E_{R}} \frac{E}{N} \frac{1}{112} .
\end{gathered}
$$

This fraction is computed by marital status for all males and females between ages 24 and 54 . The fractions of total household time allocated to the market by married households, $\tilde{l}^{m}$, and by single households, $\tilde{l}^{s}$, are then calculated as the averages across male and female hours. Thus, an observation for $\tilde{l}_{t}^{m}$ and $\tilde{l}_{t}^{s}$ is obtained for each decade $t$ between 1950 and 1990, inclusive.

Figure 4, wages. The series for disposable personal income from the National Income and Product Accounts is taken and divided through by hours worked by full-time and part-time employees, both available from the Bureau of Economic Analysis, U.S. Department of Commerce.

Figure 6. The fraction of females living with a male is defined to be the fraction of females who are married plus the fraction of females who are unmarried living with a male. The size of this latter group is tabulated using the Census Bureau's "posslq" household variablepersons of the opposite sex sharing living quarters. This variable unfortunately also includes people who are not partners. Still, it probably is a good proxy for the number of cohabitations. Note that the number of unmarried couples living together before 1960 would have been small and can be safely ignored.

Figures 8 and 9. The facts displayed in these graphs are again based on tabulations from Census data downloaded from IPUMS-USA. In figure 8 the adjustment for the shift in the age distribution is done using the typical method employed by demographers. Let $p$ denote the total female population at a point in time. Suppose that this population is made up of $I$ age groups. Define $p_{i}$ to represent the number of women 
in the $i$ th age group and allow $m_{i}$ to proxy for the number of these women who are married. The fraction of married females in the total population is then given by

$$
f=\sum_{i=1}^{I} \frac{m_{i}}{p_{i}} \frac{p_{i}}{p} .
$$

Hence, $f$ depends both on the age composition of the population (or the $p_{i} / p$ terms) and on the fraction of each age group who are married (or the $m_{i} / p_{i}$ terms). Now, for any year $t$, define an age-adjusted measure by

$$
\hat{f}_{t}=\sum_{i-1}^{I} \frac{m_{i, t}}{p_{i, t}} \frac{p_{i, 2000}}{p_{2000}} .
$$

Thus, $\hat{f}_{t}$ calculates the fraction of women who would be married if the age composition of 2000 was in effect at time $t$. In figure 9 an independent single female is defined to be a never-married woman who is either the head of a household or the friend or partner of a householder. The curve labeled "single, on own" graphs this group relative to all single females. The curve marked "married" shows the number of married females relative to the number of married plus independent single ones. The plots in figure 9 are restricted to women in the 18-30 age group.

Table 5, labor force participation rate for 1920. Prior to 1940 it is not possible to obtain hours-worked data for married and single females. Thus, for 1920 labor force participation rates are used instead. This is done by heroically assuming that the workweek is fixed at 40 hours and that there are 112 nonsleeping hours in a week. It is also assumed that all males work a 40-hour week. Denote the rates of participation for married and single females by $f_{1920}^{m}$ and $f_{1920}^{s}$. Then, for the model, $f_{1920}^{m}$ and $f_{1920}^{s}$ can be obtained from hours worked, $h_{1920}^{m}$ and $h_{1920}^{s}$, by using the formulas

$$
\frac{2-h_{1920}^{m}}{2}=\frac{40+40 \times f_{1920}^{m}}{2 \times 112} \text { and } 1-h_{1920}^{s}=\frac{40+40 \times f_{1920}^{s}}{2 \times 112} .
$$

Table 6. The numbers in the table for the U.S. data are derived as follows: First, the counts for the fractions of females who are married, $m$, are taken from the data displayed in figure 8. Second, in the model only never-married females live at home. Suppose that this is true in the data as well. The number of never-married females at home is given by the formula for $y$. Third, $s=1-\int d \mathbf{M}(b)-y$. All numbers in the table refer to women in the 18-64 age group and have been adjusted to control for shifts in the age distribution of the population (in the manner discussed above). Fourth, to calculate average household size for the 
U.S. data, simply take the size of the 18-64 population and divide it through by the number of independent households. The same thing can be done for the model by using the formula $2 /\left[2 s+\int d \mathbf{M}(b)\right]$.

Table 7. Household size is the population between the ages of 18 and 64 per household. For the United States, the data come from the 2000 Census. For all other countries EUROSTAT data on population and social conditions for the year 2001 are used. For the United States the relative price of household appliances is defined to be the price index for kitchen and other household appliances relative to the one for personal consumption expenditures (taken from the National Income and Product Accounts). For the rest, EUROSTAT's Harmonized Indices of Consumer Prices (HICP) is used to calculate the price index for household appliances (cp053) relative to one for all items-HICP (cp00). GDP per capita (in purchasing power parity U.S. dollars) and the gender gap are the 2001 values given in the Human Development Report (2003). The product market regulation index, with higher values indicating more regulation, is for the year 1998. The source is Conway, Janod, and Nicoletti (2005). Religion represents the fraction of people who classify themselves as religious in the 2000 World Values Survey.

\section{Endnotes}

Daron Acemoglu, Alvaro Aguirre, Kei Muraki, Claudia Olivetti, and Juan Sanchez are thanked for helpful comments. Financial support from the Ministerio de Educacion y Ciencia (grant SEJ200765169) and the National Science Foundation is gratefully acknowledged. Greenwood and Guner (2008) present additional material on the theory developed, supplement the simulation with sensitivity analysis, and provide extra discussion of the cross-country evidence.

1. Data sources, and issues regarding the facts and matching them with the model to be developed, are detailed in the appendix.

2. The impact of technological progress on household formation was addressed some time ago in a classic and prescient book by Ogburn and Nimkoff (1955). The book analyzes the impact of technological progress on family size, marriage and divorce, and female labor force participation, among other things.

3. Ogburn and Nimkoff $(1955,40-41)$ quote Godey's Lady's Book in 1831 as writing that "No sensible man ever thought a beautiful wife was worth as much as one that could make good pudding" or in 1832 as stating that "Among our industrious fore-fathers it was a fixed maxim that a young lady should never be permitted to marry until she had spun for herself a set of body, bed and table linen. From this custom all unmarried women are called spinsters in legal proceedings."

4. Note that when a single agent dies, he is replaced by another single agent. This explains why there is no term reflecting the probability of dying multiplying $s_{-1}$ in the formula for $\mathbf{M}(b)$.

5. The proof of lemma 2 contained in Greenwood and Guner (2008) makes this clear.

6. The important parameter is the elasticity of substitution between goods and time in production, $1 /(1-\kappa)$. Chang and Schorfheide (2003) also find that goods and time are substitutes in the household production function. Their estimate is not far off from McGrattan et al.'s (1997). 
7. There are not any recent estimates for the duration of marriages. Schoen and Standish (2001) estimate the duration of marriages to be about 24 years in 1995, whereas Espenshade (1985) estimates it to be 22.5 years for white females and 14.6 for black females over the period 1975-80. The steady-state duration of marriages in the model is given by

$$
d_{m}=\frac{1}{1-\pi_{m m}(1-\delta)},
$$

where $\pi_{m m}$ is the probability of a married agent remaining married next period.

8. In line with the discussion surrounding lemma 2, the compensating differential needed to make a single as well off as a married person falls only from $20.7 \%$ to $17.7 \%$. This small decline is due to the fact that the fixed cost, $\mathbf{c}$, is only a small fraction of the value of a single's time endowment, $w$. Choo and Siow (2006) estimate a nontransferable utility model of the U.S. marriage market. Their estimates show that the gains to marriage for young adults fell sharply between 1971 and 1981.

9. See Lam (1997) for some facts on the correlation of income levels across partners and Schwartz and Mare (2005) for education.

10. Wallace (2000) finds that the decline in the marriage rate is inversely related to the level of education.

\section{References}

Albanesi, Stefania, and Claudia Olivetti. 2006. "Gender Roles and Technological Progress." Manuscript, Boston University.

Algan, Yann, and Pierre Cahuc. 2007. "The Roots of Low European Employment: Family Culture?" NBER International Seminar on Macroeconomics 2005:65-109.

Andolfatto, David, and Glenn M. MacDonald. 1998. "Technology Diffusion and Aggregate Dynamics." Review of Economic Dynamics 1 (April): 338-70.

Becker, Gary S. 1965. "A Theory of the Allocation of Time." Economic Journal 75 (September): 493-517.

Bethencourt, Carlos, and Jose-Victor Rios-Rull. 2009. "On the Living Arrangements of Elderly Widows." International Economic Review 50 (August), forthcoming.

Cavalcanti, Tiago V. de V., and Jose Tavares. 2008. "Assessing the 'Engines of Liberation': Home Appliances and Female Labor Force Participation." Review of Economics and Statistics 90, no. 1:81-88.

Chang, Yongsung, and Frank Schorfheide. 2003. "Labor-Supply Shifts and Economic Fluctuations." Journal of Monetary Economics 50 (November): 1751-68.

Choo, Eugene, and Aloysius Siow. 2006. "Who Marries Whom and Why." Journal of Political Economy 114 (February): 175-210.

Clarke, Sally C. 1995a. "Advance Report of Final Divorce Statistics, 1989 and 1990." Monthly Vital Statistics Reports 43 (suppl.; March).

—. 1995b. "Advance Report of Final Marriage Statistics, 1989 and 1990." Monthly Vital Statistics Reports 43 (suppl.; July).

Coen-Pirani, Daniele, Alexis Leon, and Steven Lugauer. 2008. "The Effect of Household Appliances on Female Labor Force Participation: Evidence from Micro Data." Manuscript, Carnegie Mellon University.

Conway, Paul, Veronique Janod, and Guiseppe Nicoletti. 2005. "Product Market Regulation in OECD Countries: 1998 to 2003." Working Paper no. 419, Economics Department, OECD, Paris.

Cooley, Thomas F., and Edward C. Prescott. 1995. "Economic Growth and Business Cycles." In Frontiers of Business Cycle Research, ed. Thomas F. Cooley, 1-38. Princeton, NJ: Princeton University Press. 
Cornwell, Christopher, and Peter Rupert. 1997. "Unobservable Individual Effects, Marriage and the Earnings of Young Men." Economic Inquiry 35 (April): 285-94.

Espenshade, Thomas J. 1985. "Marriage Trends in America: Estimates, Implications, and Underlying Causes." Population and Development Review 11, no. 2:193-245.

Greenwood, Jeremy, and Nezih Guner. 2008. "Marriage and Divorce since World War II: Analyzing the Role of Technological Progress on the Formation of Households." IZA Discussion Paper no. 3313, Institute for the Study of Labor, Bonn.

Lam, David. 1997. "Demographic Variables and Income Inequality." In Handbook of Population and Family Economics, ed. Mark R. Rosenzweig and Oded Stark, 1015-59. Amsterdam: Elsevier Science.

McGrattan, Ellen R., and Richard Rogerson. 1998. "Changes in Hours Worked since 1950." Federal Reserve Bank of Minneapolis Quarterly Review 22 (Winter): 2-19.

McGrattan, Ellen R., Richard Rogerson, and Randall Wright. 1997. “An Equilibrium Model of the Business Cycle with Household Production and Fiscal Policy." International Economic Review 38 (May): 267-90.

Mortensen, Dale T. 1988. "Matching: Finding a Partner for Life or Otherwise." American Journal of Sociology 94 (suppl.): S215-S240.

Ogburn, William F., and Meyer F. Nimkoff. 1955. Technology and the Changing Family. Boston: Houghton Mifflin.

Reid, Margaret G. 1934. Economics of Household Production. New York: Wiley.

Schoellman, Todd, and Michele Tertilt. 2007. "Household Size and the Demand for Private Goods: United States 1850-2000." Manuscript, Stanford University.

Schoen, Robert. 1983. United States Marital Status Life Tables for the Period 19101975 and Cohorts Born 1888-1945. Washington, DC: National Technical Information Service.

Schoen, Robert, and Nicola Standish. 2001. "The Retrenchment of Marriage: Results from Marital Status Life Tables for the United States, 1995." Population and Development Review 27 (September): 553-63.

Schwartz, Christine R., and Robert D. Mare. 2005. "Trends in Educational Assortative Marriage from 1940 to 2003." Demography 42 (November): 621-46.

Stevenson, Betsey, and Justin Wolfers. 2007. "Marriage and Divorce: Changes and Their Driving Forces." Journal of Economic Perspectives 21 (Spring): 27-52.

United Nations Development Programme. 2003. Human Development Report. New York: Oxford University Press.

U.S. Bureau of Labor Statistics. 2007. Consumer Expenditure in 2005. Report no. 998. Washington, DC: U.S. Department of Labor.

Wallace, Geoffrey L. 2000. "An Assessment of Several Explanations for the Decline in Marriage." Manuscript, La Follette School of Public Affairs, University of Wisconsin.

Wolfers, Justin. 2006. “Did Unilateral Divorce Laws Raise Divorce Rates? A Reconciliation and New Results." American Economic Review 96 (December): 1802-20. 


\section{Erratum Sheet, NBER (GG, 2009)}

- Pg 246, eq. 9: left-hand side should read

$$
\frac{d\left(u^{m}-u^{s}\right)}{d p}=\cdots
$$

and not

$$
\frac{d\left(u^{m}-u^{s}\right)}{d w}=\cdots
$$

